GIS-Assisted Spatial Data Management for Corps of Engineers Real Estate Activities

Linda Peyman Dove, Mark R. Graves, and Evelyn Lopez
August 2001 
The contents of this report are not to be used for advertising, publication, or promotional purposes. Citation of trade names does not constitute an official endorsement or approval of the use of such commercial products.

The findings of this report are not to be construed as an official Department of the Army position, unless so designated by other authorized documents. 


\section{GIS-Assisted Spatial Data Management for Corps of Engineers Real Estate Activities}

by Linda Peyman Dove, Mark R. Graves

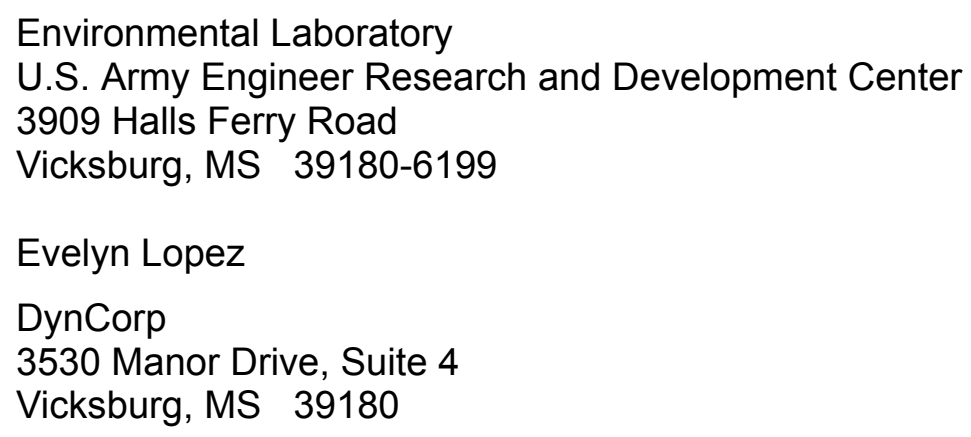

Final report

Approved for public release; distribution is unlimited

$\begin{array}{ll}\text { Prepared for } & \text { U.S. Army Corps of Engineers } \\ & \text { Washington, DC 20314-1000 } \\ \text { Under } & \text { Work Unit } 33181\end{array}$




\section{Contents}

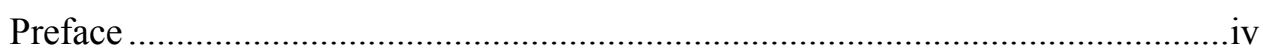

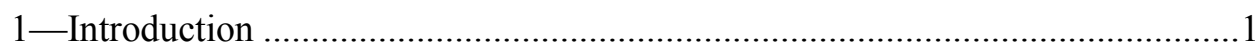

2-A Cadastre Real Estate GIS Database Design ..................................................2

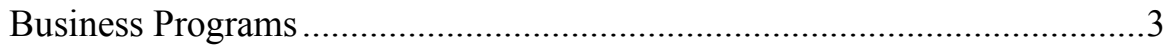

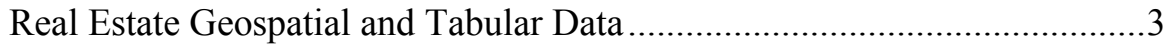

CADD/GIS Technology Center Spatial Data Standards ...............................4

3-A Cadastre Real Estate GIS Software Tool ...................................................6

4-Implementation of a Cadastre Real Estate GIS at a Corps Lake ......................

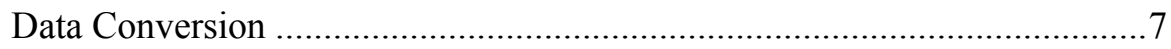

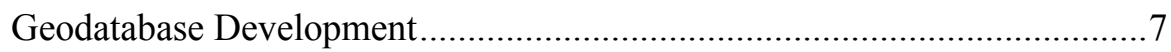

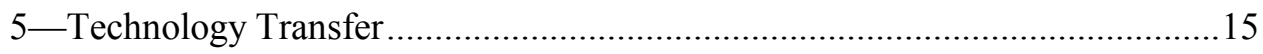

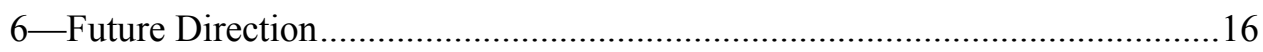

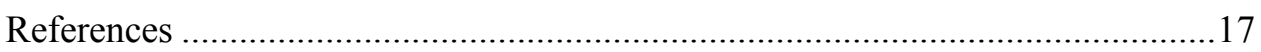

Appendix A: New Tables Added to SDS Version 2.0 .....................................A1

Appendix B: Instructions for Using the Cadastre Real Estate GIS

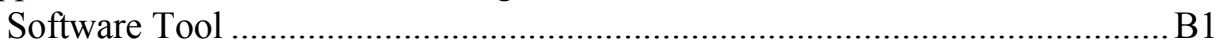

SF 298 


\section{Preface}

This report was prepared as part of the Geospatial Technology Research and Development Program Work Unit 33181, GIS-Assisted Spatial Data Management for CE Real Estate Activities. Research was conducted by the Environmental Laboratory (EL), U.S. Army Engineer Research and Development Center (ERDC). The research was sponsored by Headquarters, U.S. Army Corps of Engineers (HQUSACE), and was carried out during the period October 1998 to September 2001.

This report was prepared by Dr. Linda Peyman Dove and Mr. Mark R. Graves, Environmental Systems Branch (ESB), EL, and Ms. Evelyn Lopez, DynCorp Corporation. Dr. Rose Kress was principal investigator for this project. She was active in the development of the Cadastre Real Estate database design and Geographical Information System (GIS) Real Estate Workshops. Ms. Nancy Towne, ERDC, Information Technology Laboratory (ITL), was instrumental in the development of the Cadastre Real Estate database design and incorporated the design into the Spatial Data Standards (SDS) version 2.0. Mr. Randall Mayne, Fort Worth District, served as a partner in this research. He provided technical expertise in developing the Cadastre Real Estate database design, provided a prototype GIS data set of cadastral real estate and ancillary data for Lake of the Pines, Texas, and coordinated a GIS Real Estate workshop at the Fort Worth District.

The study was under the general supervision of Mr. Harold W. West, Chief, ESB; Dr. Dave Tazik, Chief, Ecosystem Evaluation and Engineering Division, EL; and Dr. Edwin A. Theriot, Acting Director, EL. The HQUSACE technical monitors were Mr. M. K. Miles and Ms. Nancy Blyler. Reviews were provided by Mr. Harold W. West and Mr. Scott Bourne, ESB. 
At the time of publication of this report, Director of ERDC was Dr. James R. Houston. Commander and Executive Director was COL John W. Morris III, EN.

This report should be cited as follows:

Peyman Dove, L., Graves, M. R., and Lopez, E. (2001). “GISassisted spatial data management for Corps of Engineers real estate activities," ERDC/EL TR-01-22, U.S. Army Engineer Research and Development Center, Vicksburg, MS.

The contents of this report are not to be used for advertising, publication, or promotional purposes. Citation of trade names does not constitute an official endorsement or approval of the use of such commercial products. 


\section{Introduction}

Currently the U.S. Army Corps of Engineers (CE) relies primarily on hardcopy paper maps and documents to manage real estate assets. It is now widely understood that real estate data are fundamentally geospatial and that there is great advantage to managing and maintaining cadastral information in a geographic information system (GIS). Such a shift in data management would increase efficiency for storing, retrieving, processing, and editing information by all users and would make cadastral real estate data more readily available throughout the Corps and to the public. Research funded under the Corps Civil Works Research and Development Geospatial Technologies Program was initiated to avoid the development of numerous incompatible real estate GIS solutions within the Corps.

This report summarizes the results of research to develop and demonstrate a GIS-assisted approach to meet the spatial data management and analysis demands of the Corps real estate activities. The research resulted in the following products:

a. A Cadastre Real Estate GIS database design that is compliant with the CADD/GIS Technology Center Spatial Data Standards (SDS) (Information Technology Laboratory (ITL) 2001).

b. A Cadastre Real Estate GIS Software Tool ${ }^{1}$ that implements the SDScompliant Cadastre Real Estate GIS database design in the object-oriented ArcInfo 8 software and that populates the database by linking to the nonspatial Real Estate Management Information System (REMIS).

c. Implementation of a Cadastre Real Estate GIS at a Corps project.

d. Technology transfer.

A document is also being developed on issues related to data conversion, such as converting hard-copy paper maps and digital real estate data to a GIS format. The document will be posted on the technology transfer Web site when completed.

\footnotetext{
${ }^{1}$ A preliminary version of the software tool was initiated in Work Unit 33179, Linking Existing Corporate Information Systems to GIS, but the software tool was completed, tested, and documented in this work unit (Work Unit 33181).
} 


\section{A Cadastre Real Estate GIS Database Design}

The Cadastre Real Estate GIS database design was developed to be part of an Enterprise GIS implementation. Figure 1 illustrates the components considered in the database design, which addresses the needs of not only the Corps' Real Estate Division, but of all business programs that utilize cadastral real estate data. The activities that are conducted by the business programs, such as Navigation, Flood Control, and Real Estate, determine the geospatial and tabular data included in the database design. The geospatial and tabular data must use a spatial data standard to provide uniformity among offices. The SDS is the Corps of Engineers official spatial data standard.

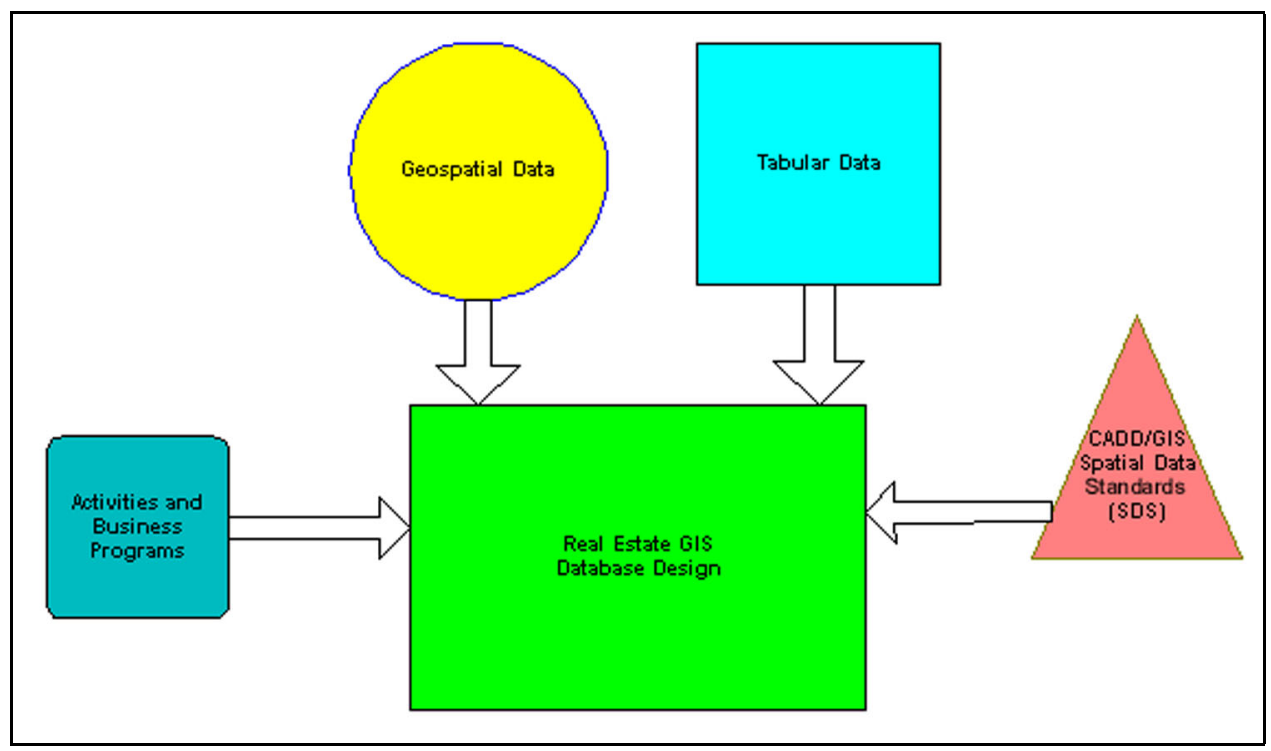

Figure 1. Components considered when developing the Cadastre Real Estate GIS database design 


\section{Business Programs}

The Real Estate GIS database design was developed by examining the needs of all business practices within the Corps that utilize real estate data. Input from Corps Project, District, Division, and Headquarters offices was solicited through workshops, e-mail distributions, and focus groups. A real estate GIS needs assessment report developed for the Rock Island District was also utilized (Stanley Consultants 1999). The intent was to develop a design that would address the needs of most programs and users by determining the theme and attributes needed to describe the real estate cadastral data.

\section{Real Estate Geospatial and Tabular Data}

The database incorporates both geospatial and tabular data (Figure 2).

Geospatial features are geographically referenced to a real-world location (the spatial part of the database). Each geospatial feature has an "attached" attribute table containing pertinent data (the tabular or non-spatial part of the database).

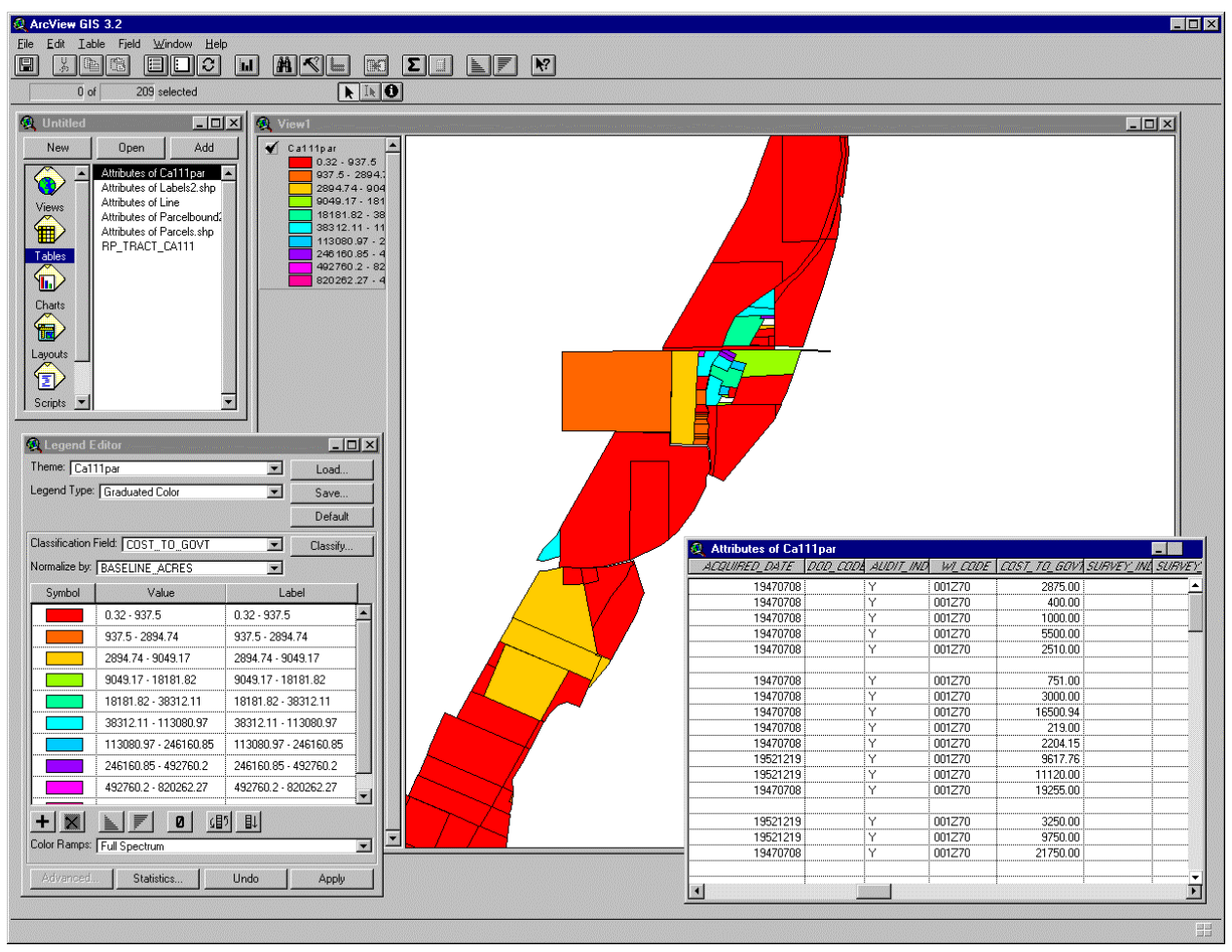

Figure 2. Sample view of the database, showing the geospatial and tabular data

The geospatial data must be developed from existing hard-copy maps or from other sources, such as existing CAD (computer-aided design) files. There are 
various options available for converting the data to digital GIS files, such as digitizing, scanning and heads-up digitizing, and using coordinate geometry. A white paper being prepared as part of this project will address the advantages and disadvantages of the different techniques.

The majority of the tabular data came from the existing Real Estate Management Information System (REMIS), created by the Corps to manage the Corps real estate holdings. It is a non-spatial database. A robust set of attributes to address the needs of most of the users was selected from various tables in the REMIS database and incorporated into the database design. This does not replace the REMIS database but allows the efficient use of the existing non-spatial REMIS database in a geospatial environment.

\section{CADD/GIS Technology Center Spatial Data Standards}

The SDS, which provides a standard for GIS implementation at Army Corps of Engineers Civil Works activities; U.S. Air Force, Army, and Navy installations; and state and local governments, was used in the development of the Cadastre Real Estate GIS database. The SDS provides standard table formats, such as data types for the fields, lengths of field values, and domains, for the themes proposed for the GIS. This provides uniformity between Corps offices, so that similar information is available in the same format.

Prior to this study, the SDS did not contain tables to fully address cadastral real estate needs, so the necessary real estate spatial data tables were developed. Initially, draft versions were developed based on input from a broad range of Corps personnel, workshops, existing studies within and outside the Corps, and real estate documents. A draft database design was presented at a workshop at the Fort Worth District. Workshop participants, including individuals from diverse professional areas and levels within the Corps, provided a review and revision of the design. A revised version was distributed for review throughout the Corps, as well as to other agencies involved in cadastral and database standards development. The draft design was updated and incorporated into the SDS version 2.0.

Five new tables were developed and added to the SDS version 2.0. The themes for the five tables are listed below.

a. Acquisition Tracts, which includes all tract boundaries for all land acquired by fee or less-than-fee transactions. Fee acquisitions are lands that the Corps has purchased, while less-than-fee acquisitions are lands that the Corps has purchased the right to use via, for example, easements, leases, or permits.

b. Outgrants, which includes the outside boundary or point location of all land outgrants. An outgrant is Corps-owned land that is leased to another party; examples of outgrants include easement, licenses, and permits. 
c. Disposals, which includes the outside boundary of all disposed land. Disposed land includes land that the Corps sells or transfers to another party.

d. Encroachments, which includes the outside boundary or point location of all encroachments. An encroachment involves the unintentional use of Corps land by another party.

e. Fee Boundaries, which includes the outside boundary of all land acquired by fee.

The SDS Data Model presents information by entity set, entity class, entity type, attribute tables, and domain tables (Information Technology Laboratory 2001). For the Cadastre Real Estate GIS database design, the entity set name is "cadastre" and the entity class name is "real estate." The entity type name, attribute table name, and domain table names depend on the entity set and entity class.

Appendix A gives the new SDS tables for the five Cadastre Real Estate GIS database themes. Each table contains fields for the name, type, and length of the attribute; the name of any domain tables used for the attribute; the name of the REMIS table where the attribute is located; the name of the attribute as it appears in the REMIS table; and the definition of the attribute. 


\section{A Cadastre Real Estate GIS Software Tool}

A software tool was written to automate the generation of a Cadastre Real Estate GIS. This tool utilizes the ArcGIS 8.1 software (ESRI 2001) and creates a personal geodatabase. Detailed instructions for this tool are found in Appendix B. The tool performs the following tasks:

a. Generates a personal Cadastre Real Estate geodatabase.

b. Generates SDS-compliant Cadastre Real Estate tables, relationships between tables, and domain values within the geodatabase.

c. Adds the geographic features (e.g. tracts, outgrant boundaries, disposal boundaries, encroachment boundaries, and fee boundaries) from existing ArcInfo shapefiles or coverages to the geodatabase.

d. Links the geodatabase to the REMIS Oracle database to retrieve the appropriate records to populate the SDS-compliant Cadastre Real Estate tables in the personal geodatabase. This tool provides a one-way link to REMIS; it does not make changes, updates, or deletions to the REMIS database. REMIS users will continue to enter and modify data using the existing REMIS interface.

e. Allows the user to manually input attribute data into the tables (e.g. for attributes that are not in the REMIS database or are not populated in the REMIS database).

f. Populates the area and perimeter attributes based on the geospatial data.

g. Deletes records in the personal geodatabase tables that no longer exist in the REMIS Oracle database. 


\section{Implementation of a Cadastre Real Estate GIS at a Corps Lake}

The Fort Worth District, Corps of Engineers, has been a partner in the Cadastre Real Estate GIS project. Lake of the Pines, Texas, served as a prototype site at which the SDS-compliant Cadastre Real Estate GIS database design was implemented using the software tool.

\section{Data Conversion}

Prior to their involvement in this research, the Fort Worth District had converted their hard-copy segment maps for Lake of the Pines to a digital format. This was done by first scanning the segment maps, generating a raster image. A global positioning system (GPS) was used to locate survey monuments along the project boundary so that the monuments could be used to georeference the scanned segment maps. The georeferenced maps were then displayed on a computer screen, and heads-up digitizing was used to develop a vector coverage of the tract boundaries. Each tract was assigned a project identification and tract number. An ArcView shapefile was then developed from the coverage and used in conjunction with the Cadastre Real Estate GIS software tool to generate a fully functional personal geodatabase for Lake of the Pines.

Data conversion has been completed for fee and less-than-fee tracts, outgrants, and fee boundaries. It has not been completed for encroachments or disposals, so feature datasets for these two themes are not complete.

\section{Geodatabase Development}

The software tool was used to create a Cadastre Real Estate geodatabase for Lake of the Pines. The geodatabase structure is illustrated in Figure 3, with the geodatabase encompassing the entire Fort Worth District. The feature dataset includes all cadastre data within the district, while the feature classes represent 


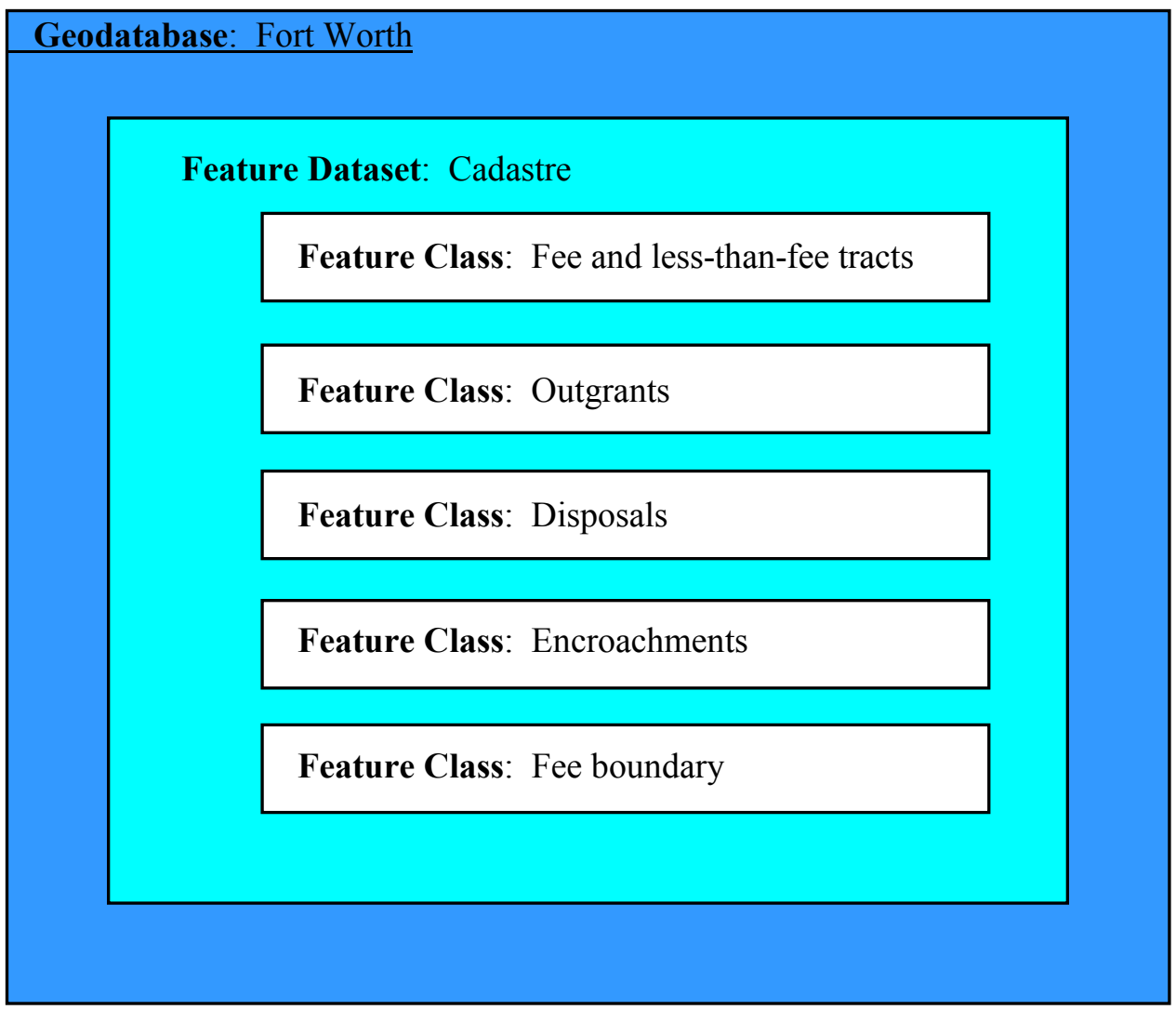

Figure 3. Personal geodatabase structure for cadastral real estate data

themes of cadastre real estate data, such as fee and less-than-fee tracts, outgrants, disposals, encroachments, and fee boundaries.

The software tool allowed the geospatial data from the ArcView shapefiles to be incorporated into the fee and less-than-fee tract, outgrant, and fee boundary feature classes. It also made a link to the REMIS database to populate the attributes in the three feature classes. 


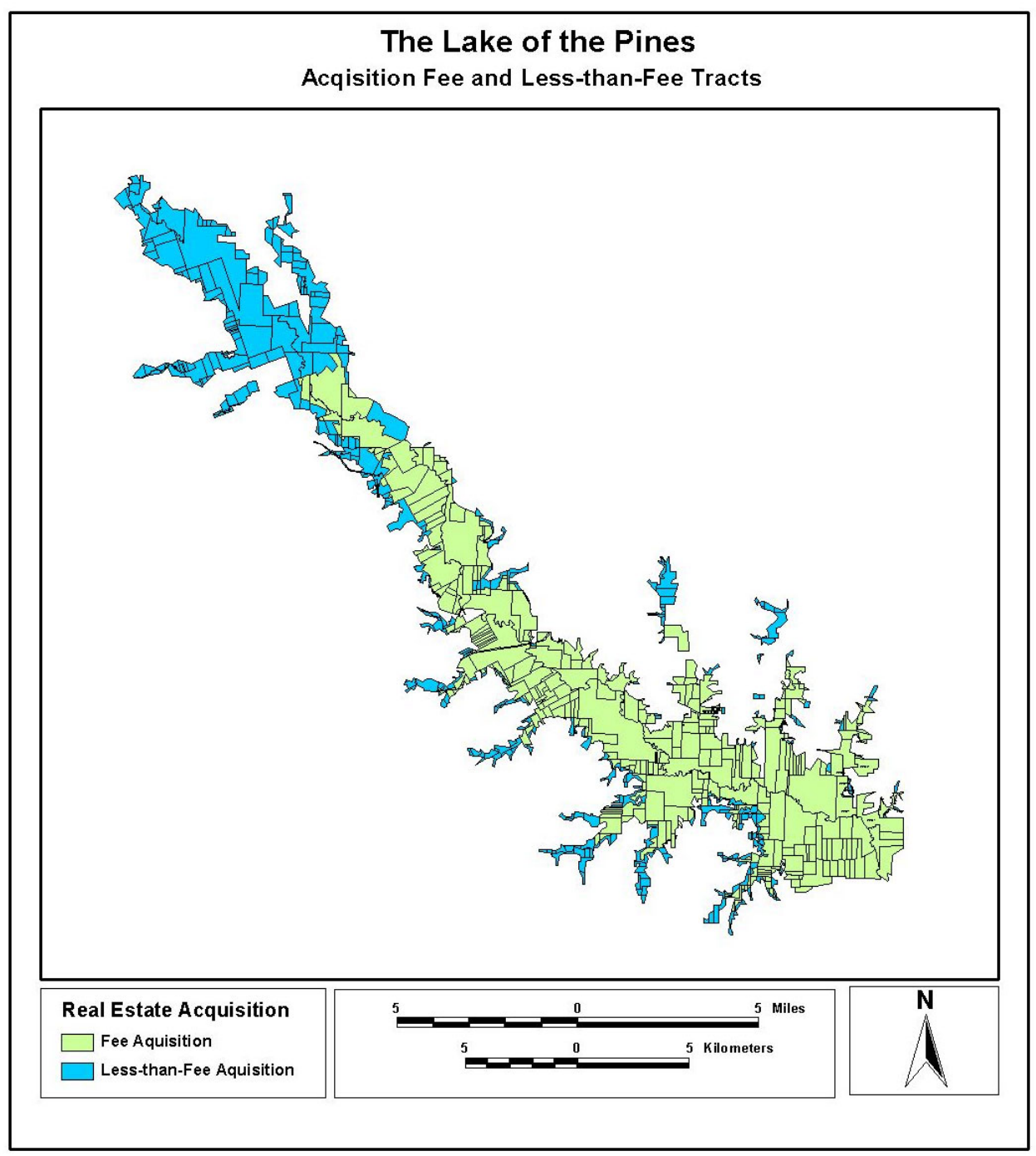

Figure 4. Tracts acquired by fee and less-than-fee for Lake of the Pines, TX

Figure 4 shows the fee and less-than-fee tracts for Lake of the Pines. The ability to query and display tracts based on the type of acquisition allows more efficient and effective management opportunities. For example, if a change in water management is being studied for a lake, the GIS can be used to determine how the affected tracts were acquired. If they were acquired by less-than-fee, the type of easement can be determined. 


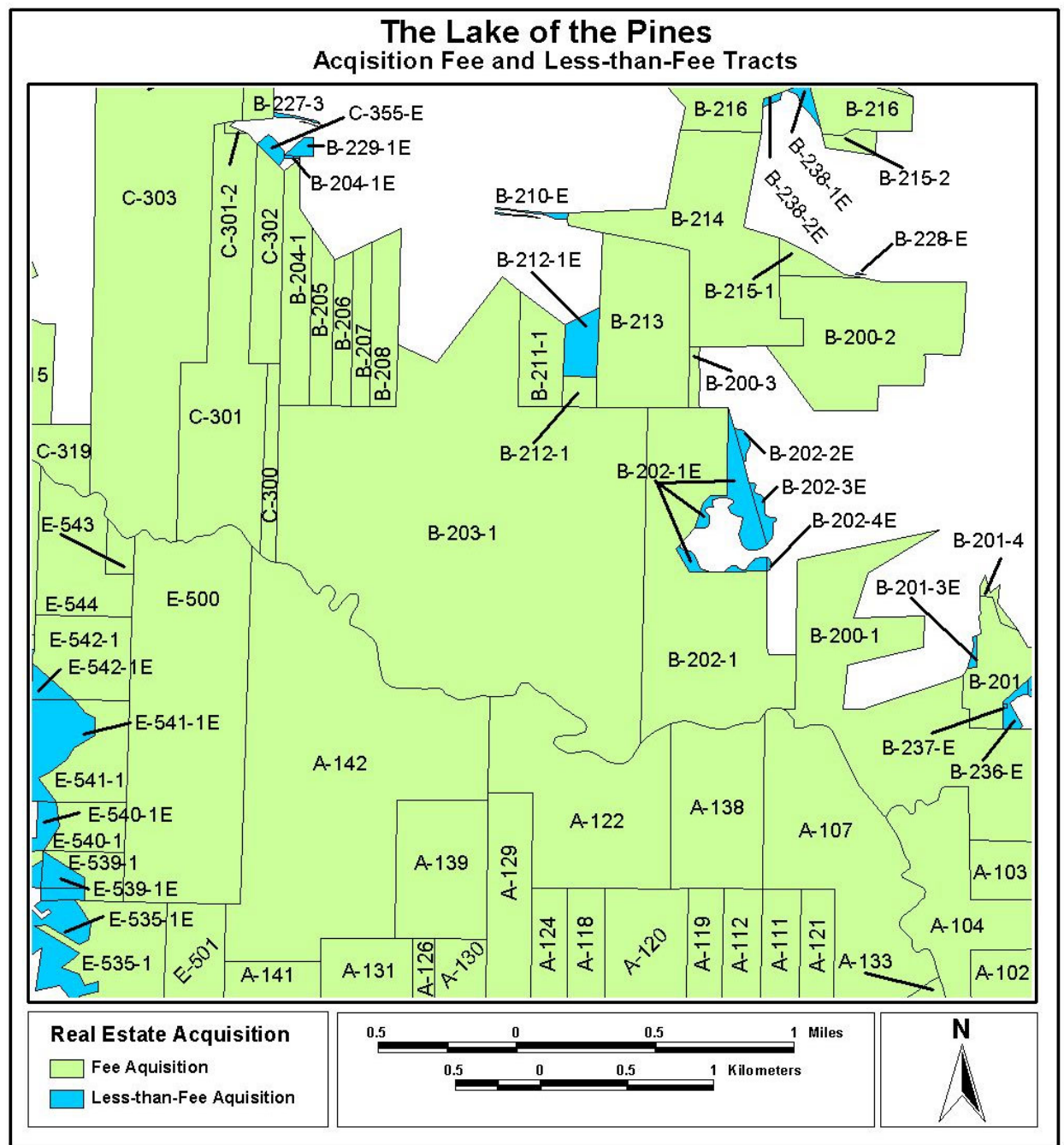

Figure 5. Blowup of one area of Lake of the Pines showing tracts labeled with the tract number and color coded depending on whether acquired by fee or less-than-fee

Areas of interest can be displayed in greater detail and labeled or color coded based on attribute values. For example, Figure 5 shows a blowup of one area of Lake of the Pines, with the tracts labeled by tract number and displayed in color according to whether they were purchased by fee or less-than-fee. 


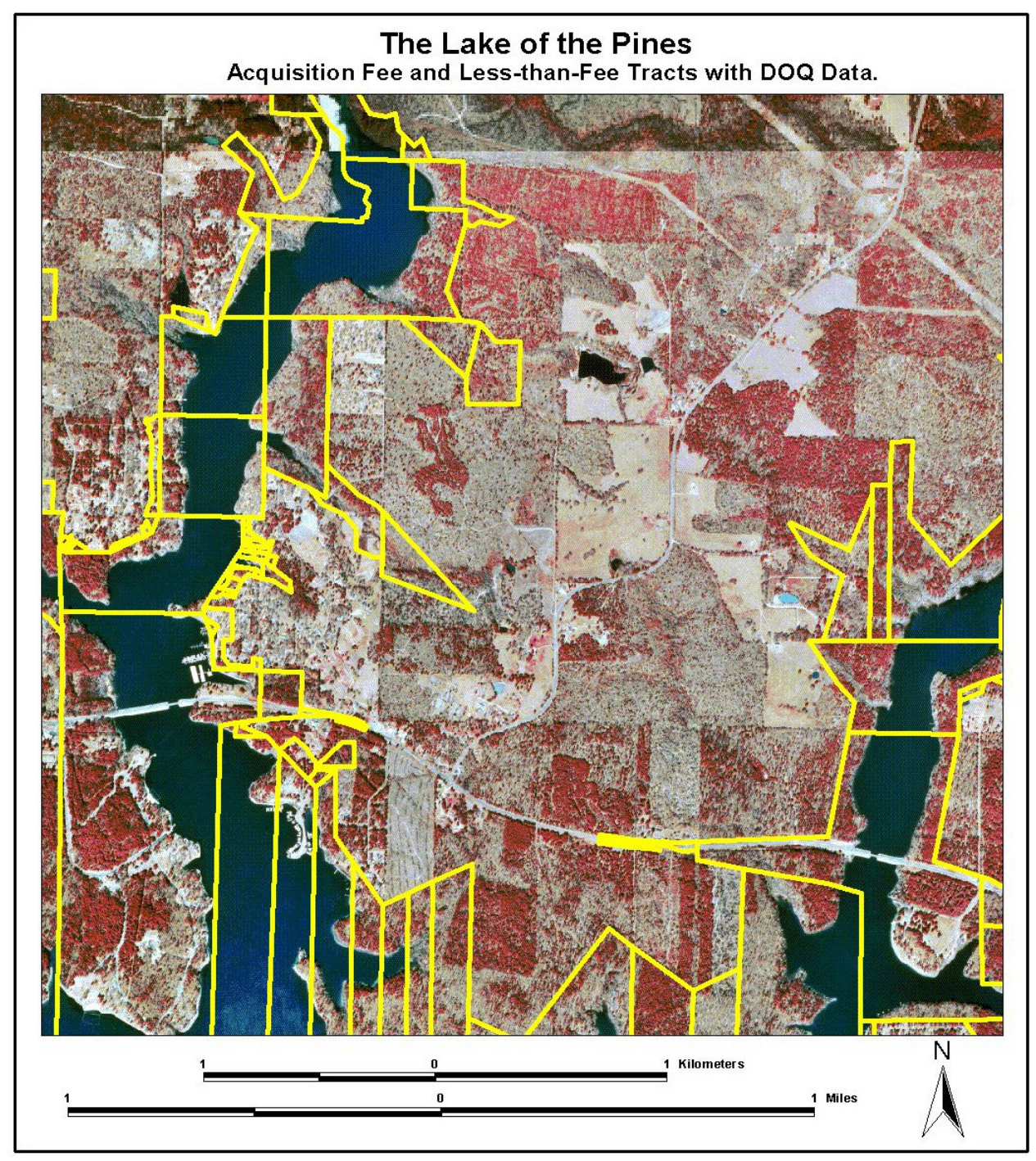

Figure 6. Project boundary tracts (shown with a solid line), with DOQ data displayed in background

By utilizing the tract maps with other data, such as digital orthographic quadrangles (DOQs), tasks such as locating tracts becomes significantly easier. For example, in Figure 6, the boundary tracts for Lake of the Pines are shown with a solid line and can be used with the DOQs to aid in maintaining project boundaries and checking for encroachments. 


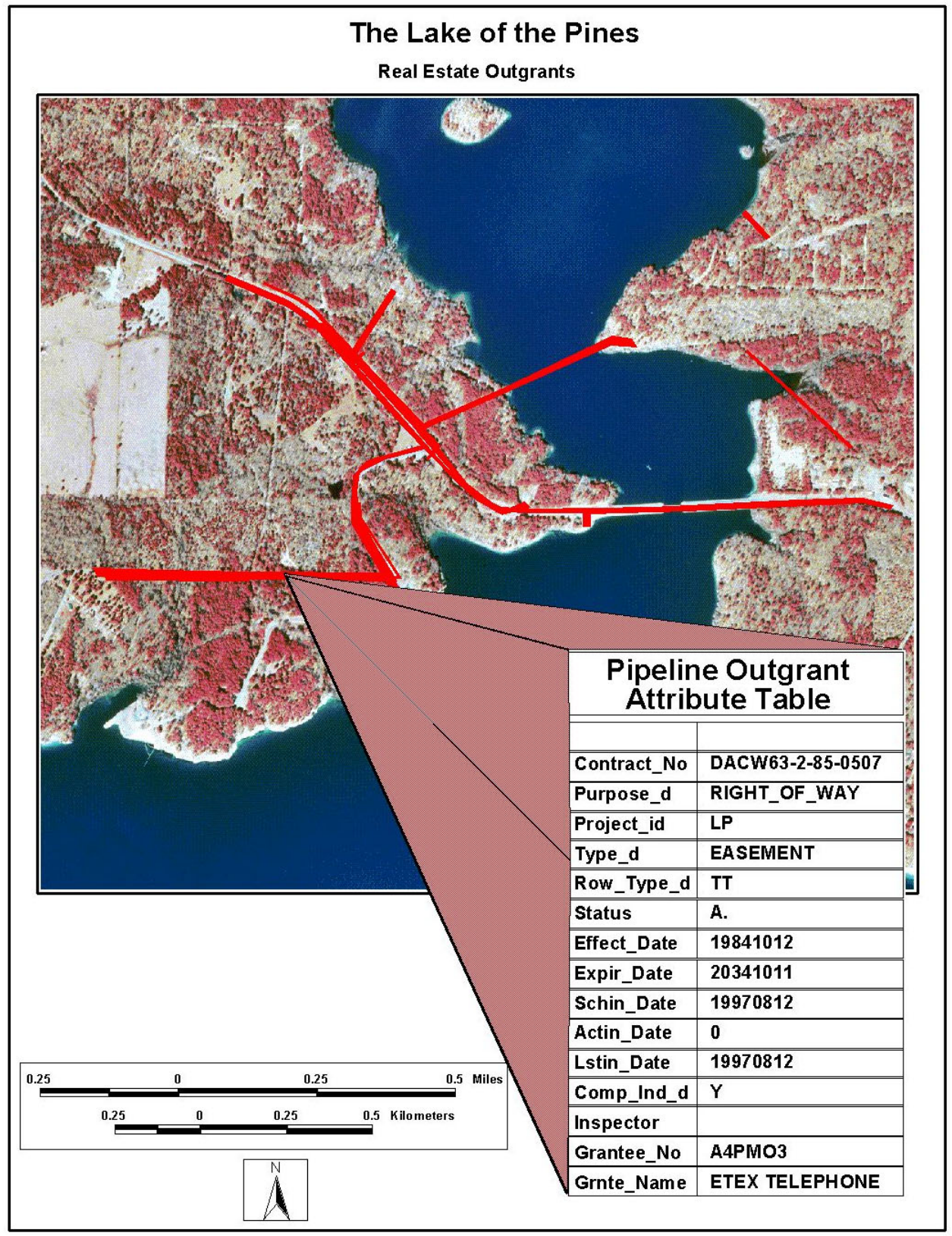

Figure 7. A portion of the outgrants for Lake of the Pines, TX

Figure 7 shows a portion of the outgrants for Lake of the Pines. Information about each outgrant can be displayed on the screen, showing tabular data such as the type of outgrant (easement, permit, etc.), status (active, inactive, terminated), effective and expiration dates, and grantee name. 


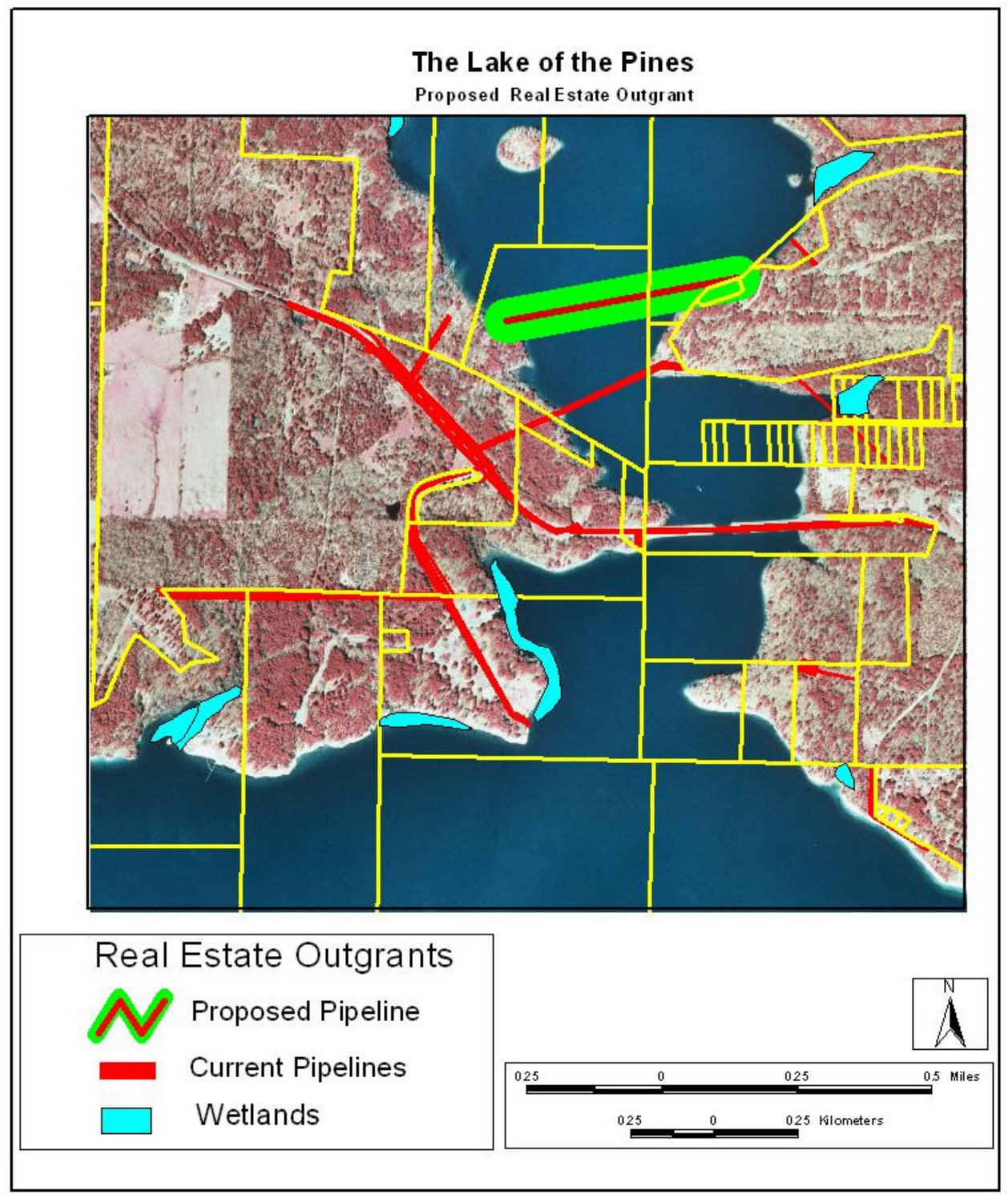

Figure 8. Proposed outgrant displayed with existing outgrant and DOQ data

The business practice of issuing an outgrant can be streamlined by having the ability to display a proposed outgrant with existing outgrants, as well as other types of infrastructure and environmental data. For example, if the project receives a request for an outgrant for a gas pipeline, the proposed pipeline can be input into the GIS. Buffers can be drawn around the proposed pipeline to determine if the pipeline construction area will impact the surrounding area or if the proposed pipeline conflicts with existing outgrants. Figure 8 shows a proposed pipeline with a 200 -foot buffer. This allows the project manager to address problems with the request at an early stage when changes in location can be made before time and resources are expended. The existing outgrants can also be queried to determine if the requester already has active, inactive, or terminated outgrants. If the requestor already has outgrants, queries such as the compliance 
status and expiration dates of those outgrants can be made and displayed graphically.

Having ready digital access to cadastral real estate data offers many possibilities to improve the way the data can be used. The ability to view and query the data in a geospatial arena can streamline decision making. The added benefit of utilizing real estate data with data such as environmental, infrastructure, or remotely sensed imagery further enhances the spatial analysis process necessary to make effective and efficient decisions.

The incorporation of cadastral real estate data was a first step in this initiative, however; it has become apparent that the addition of real property data, such as buildings, roads, picnic sites, and campsites, would also provide opportunities to improve the management of the Corps resources. 


\section{Technology Transfer}

This report, the software tool, and the instructions to install and utilize the tool have been placed on a Web site, which can be accessed at http://www.wes.army.mil/el/gdaf. On the Geospatial Data Analysis Facility home page, click "PRODUCTS." On the Products page, click on the Real Estate icon. 


\section{Future Direction}

This research has provided a GIS-assisted approach in the transition to a cadastral real estate GIS environment. This research was developed with the consideration of related projects, such as the National Integrated Land System (NILS) project, which is a collaboration between the Bureau of Land Management (BLM) and the U.S. Forest Service to produce a common data model and tool sets for managing cadastral and land record data (more information is available at http://www-a.blm.gov/nils). The NILS and its partners are working with ESRI to produce the data model and related applications based on ArcGIS Version 8.x object-oriented technology.

The research conducted was also developed in the object-oriented ArcGIS 8 software so that it would be compatible with these software models and applications developed by ESRI and the NILS project. These products are not publicly available to date, except for the ArcGIS Parcel Data Model, which is available in conceptual form. Most of the products should be available within the next year. The capabilities of models and applications and their effects on business practices related to cadastral real estate have not been assessed. Assessing these products in conjunction with the database design and software tools developed should be the next step in moving real estate data into a GIS environment.

Another step in this research process should be directed at incorporating real property into the process. The incorporation of real property such as picnic shelters, picnic tables, and fences into a GIS environment would be useful for inventory and other business purposes. 


\section{References}

Environmental Systems Research Institute, Inc. (2001). “Arc/Info (computer program)," Redlands, CA.

Information Technology Laboratory. (2001). "CADD/GIS Technology Center Spatial Data Standard, Version 2.0." U.S. Army Engineer Research and Development Center, Vicksburg, MS.

Stanley Consultants. (1999). "Real estate geographic information system needs assessment," U.S. Army Engineer District, Rock Island, Rock Island, IL. 


\section{Appendix A New Tables Added to SDS Version 2.0}




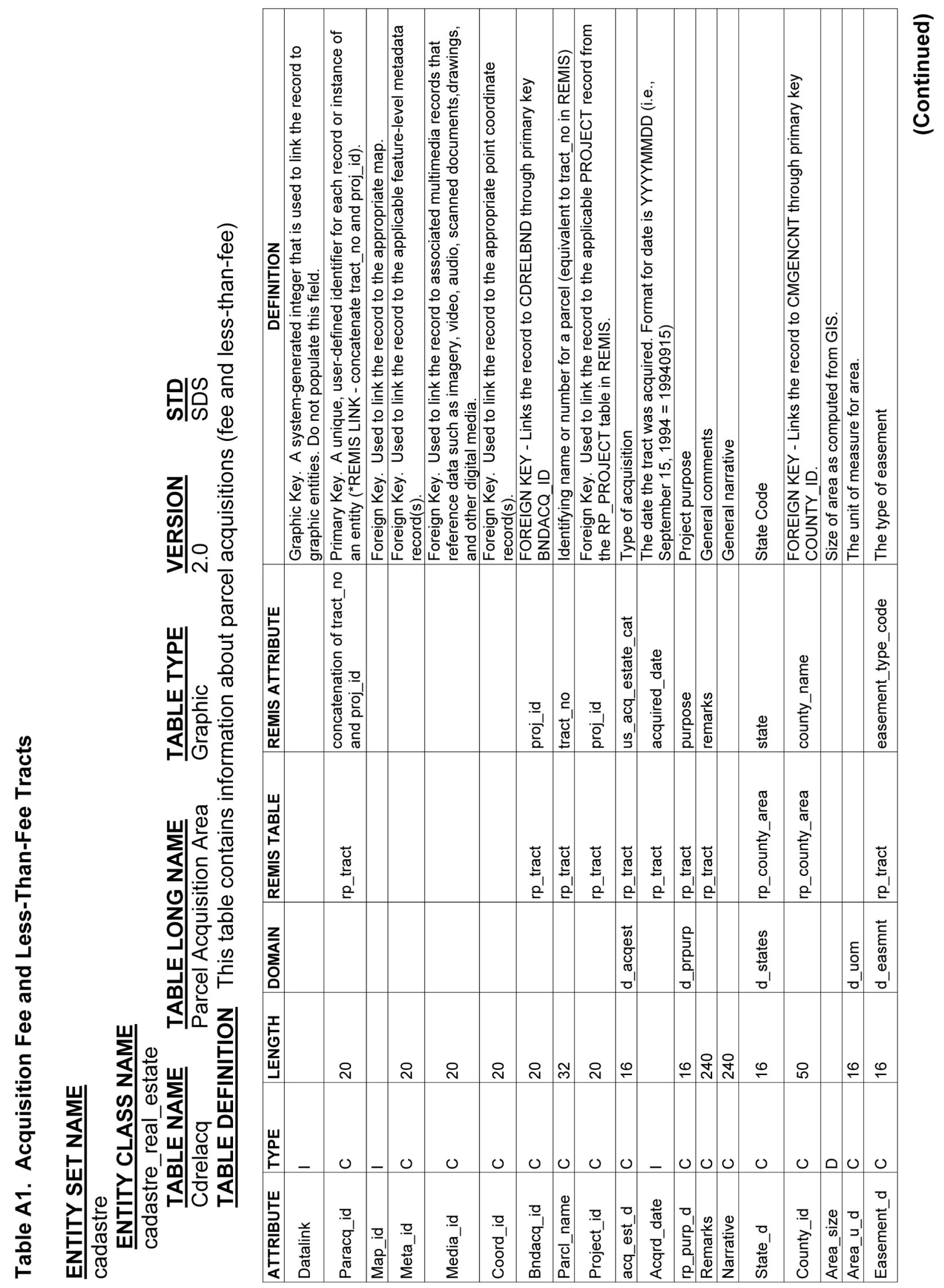




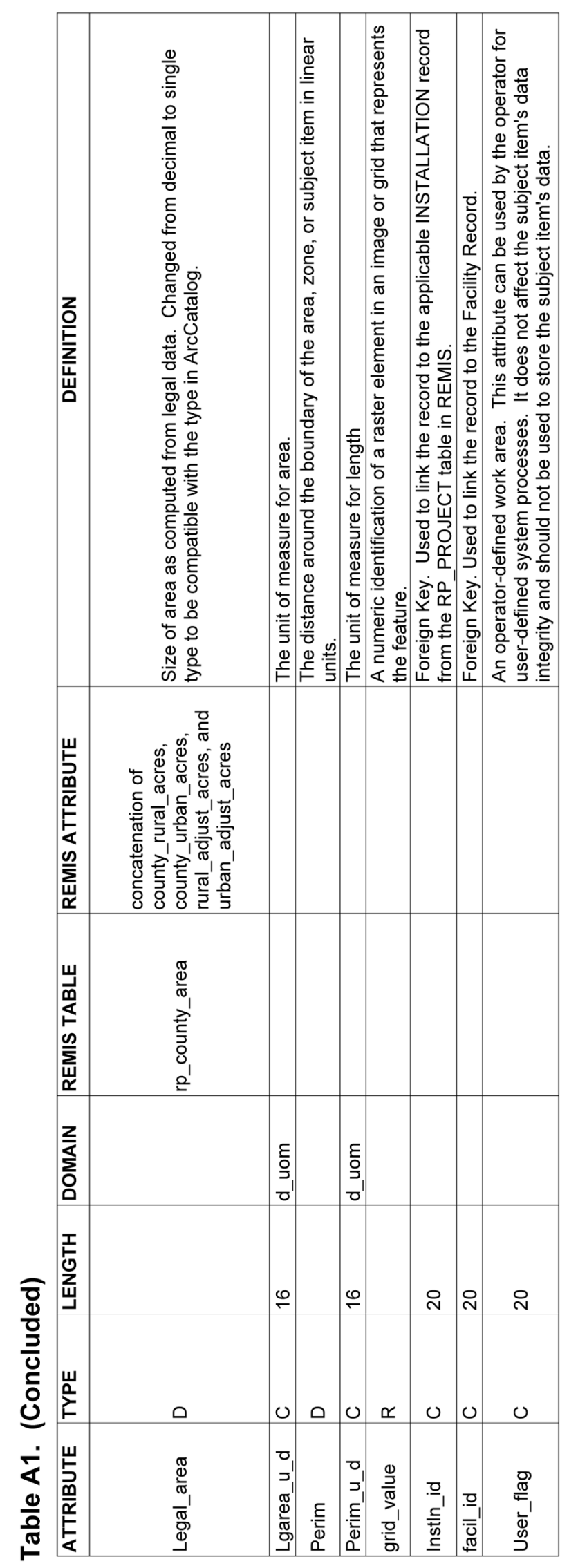

Appendix A New Tables Added to SDS Version 2.0 


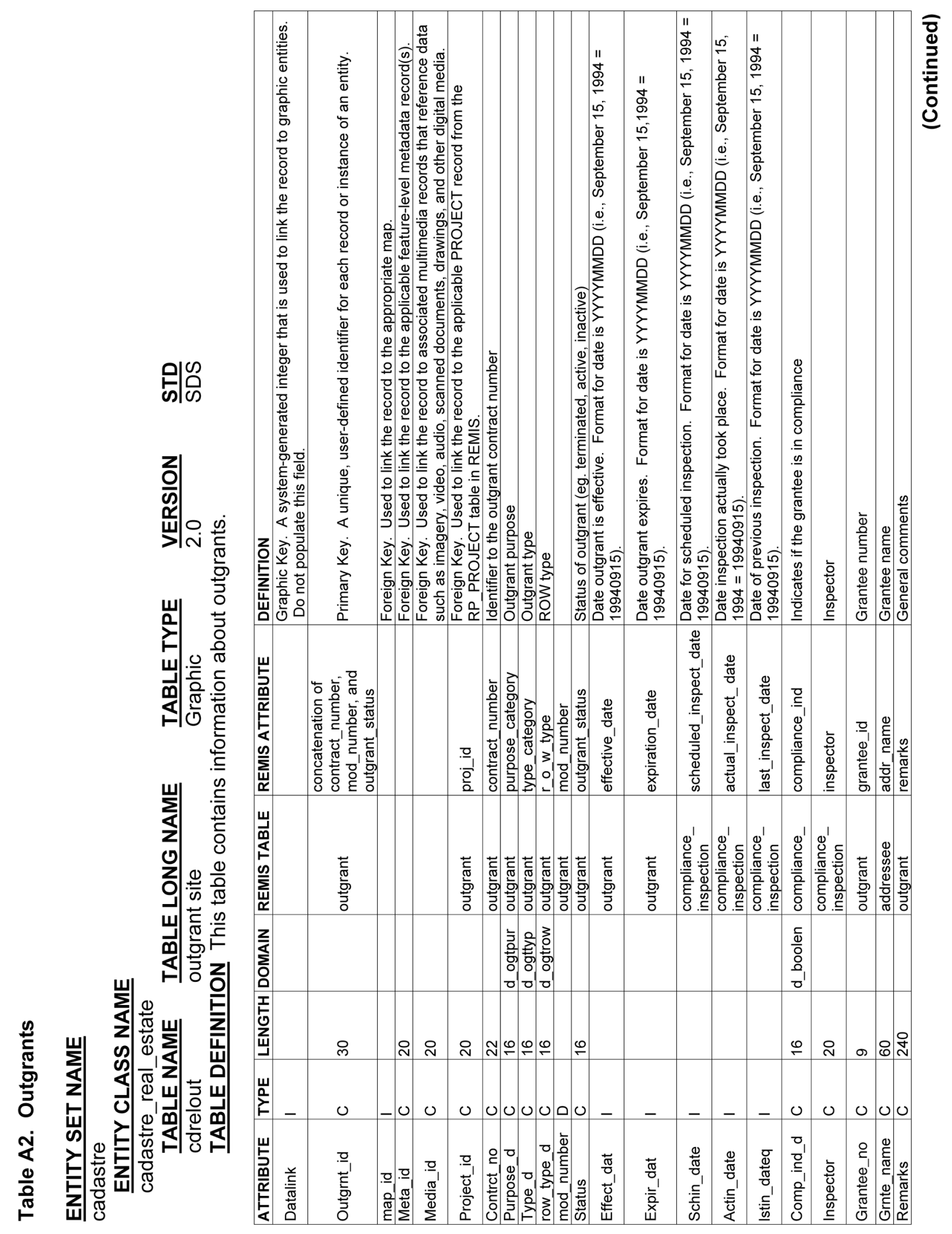




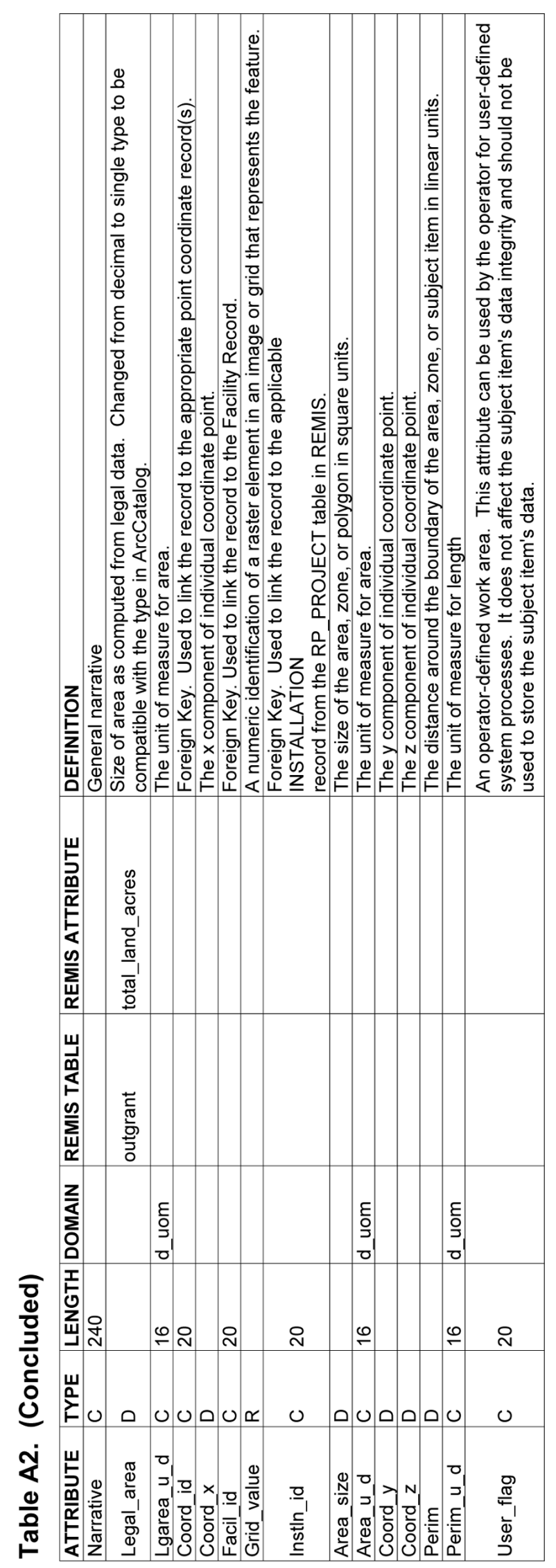

Appendix A New Tables Added to SDS Version 2.0 


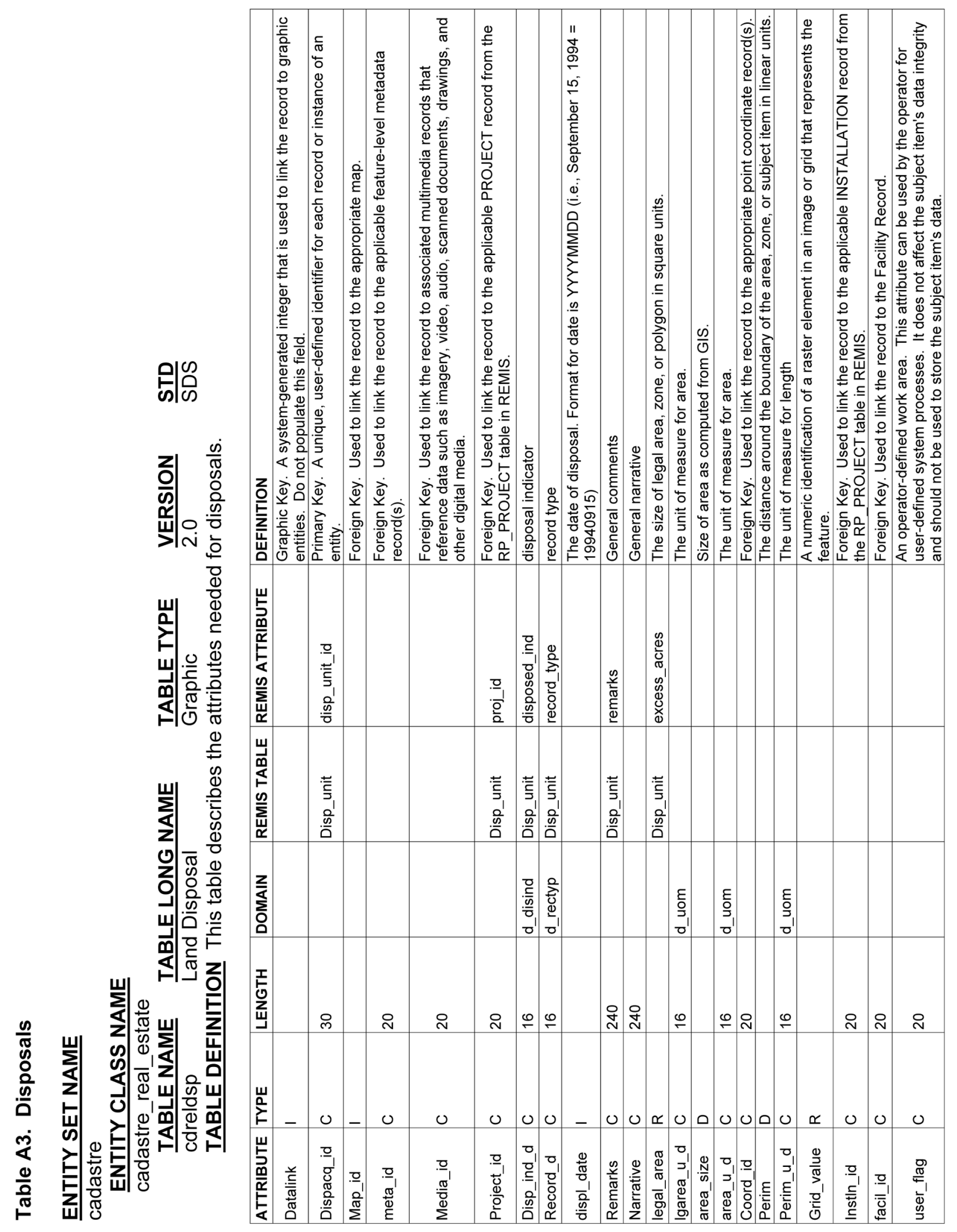




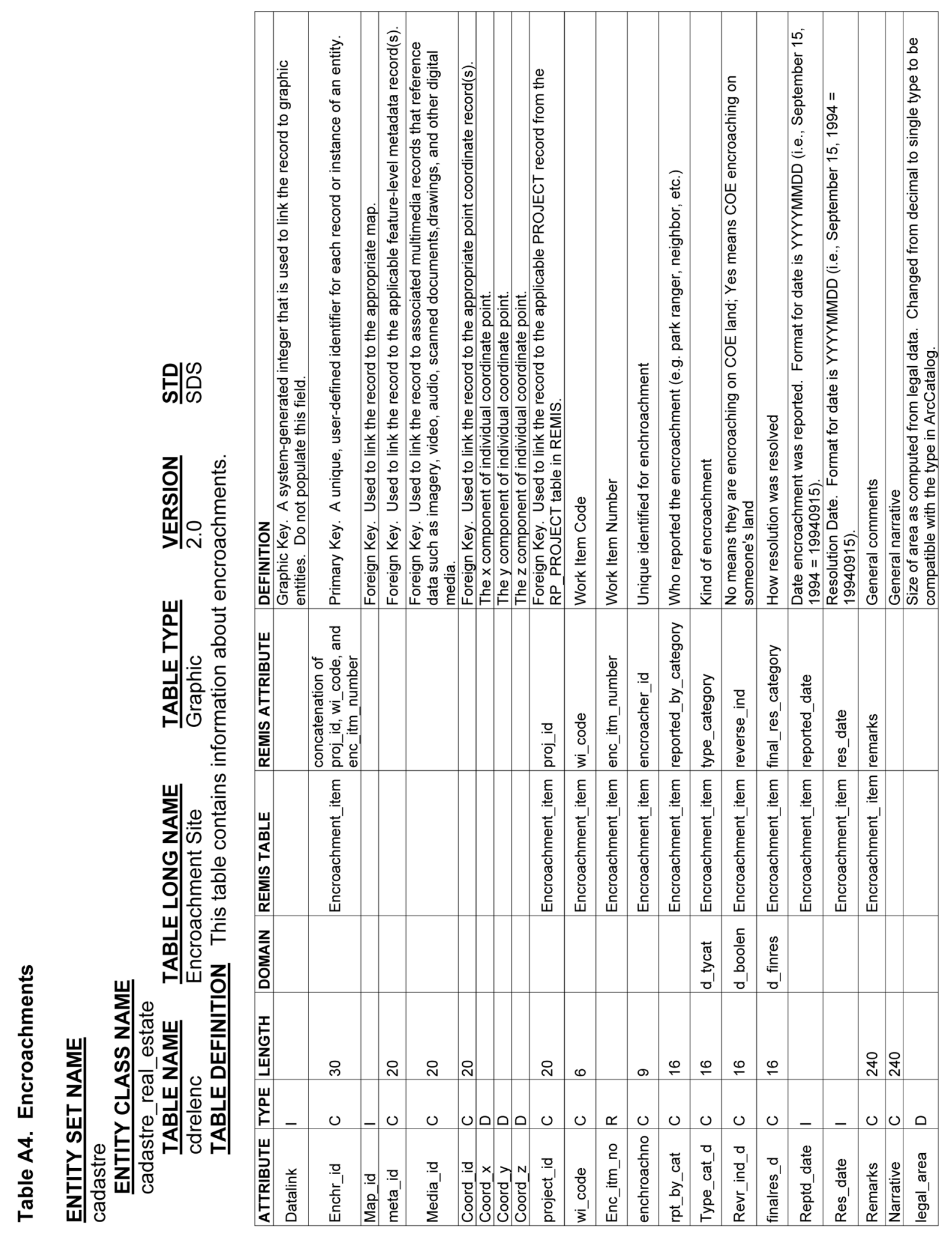




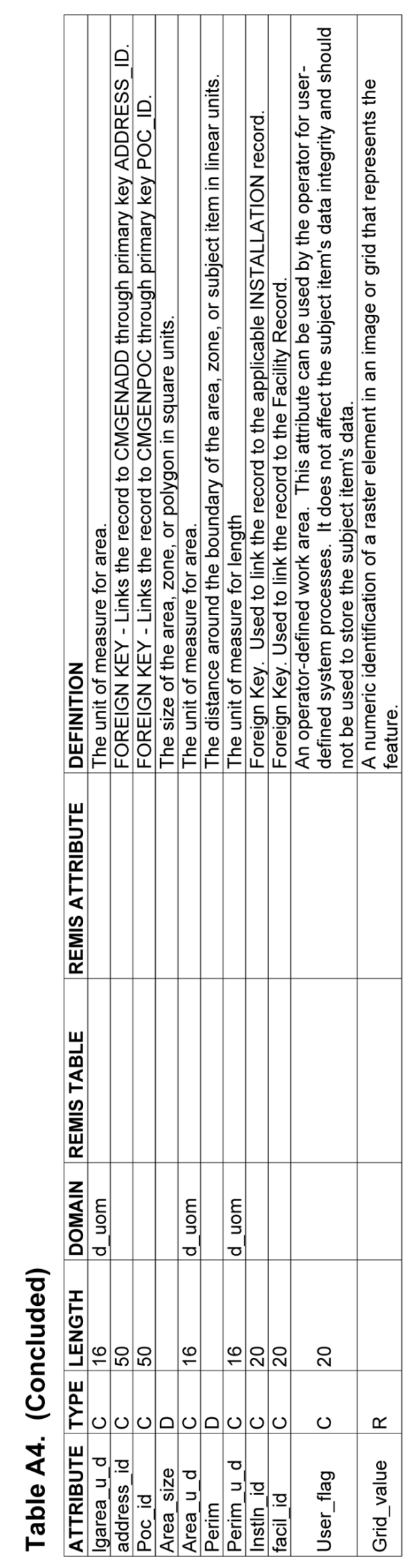




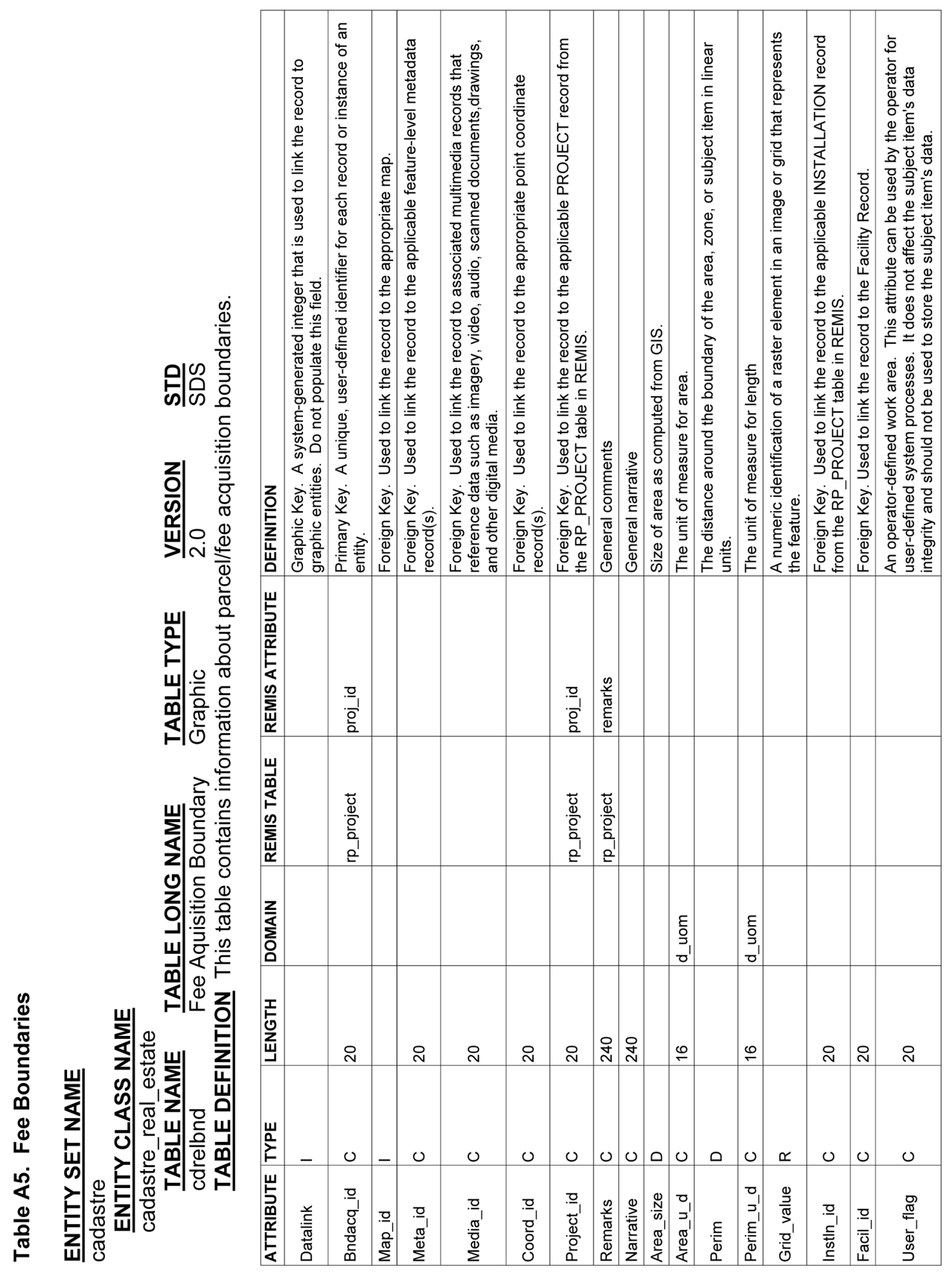




\section{Appendix B Instructions for Using the Cadastre Real Estate GIS Software Tool}

\section{Software Requirements}

a. ESRI ArcGIS 8.x desktop software (either ArcView 8.x, ArcEditor 8.x, or Arc/Info 8.x).

b. Microsoft ODBC for Oracle driver Version 2.573 (to connect to the REMIS database).

c. Oracle 8.x Client software (to set up the ODBC connection to the Oracle database).

d. Microsoft Windows NT Version 4 (SP4 or SP5) or Windows 2000. (ArcInfo 8.0.1 does not support Windows 2000 and Windows NT 4 SP 6. ArcInfo 8.0.2 and up supports both.)

e. License Manager and keycodes from ESRI (if concurrent users will be using the ESRI ArcInfo 8 software).

\section{Hardware Requirements}

a. System with a fast Pentium chip (e.g. 400+ Mhz).

b. A minimum of 128 MB RAM.

c. Fast disks (SCSI preferred).

d. True color monitor with a minimum of a 16-MB video card. 
e. Paging File (Swap space) set at a minimum of $300 \mathrm{MB}$.

\section{STEP 1: Set up Oracle Services for ODBC connection}

1. You must have Oracle Desktop installed on your system.

2. Use Oracle Net 8 Assistant (or Net8 Easy Config) on your local machine to set up the Service Name. In the example below, Net8 Easy Config (Oracle version 8.0.5) is being used. Note, the appearance of the screens or options presented may vary in later versions of Oracle. Enter Net8 Easy Config:

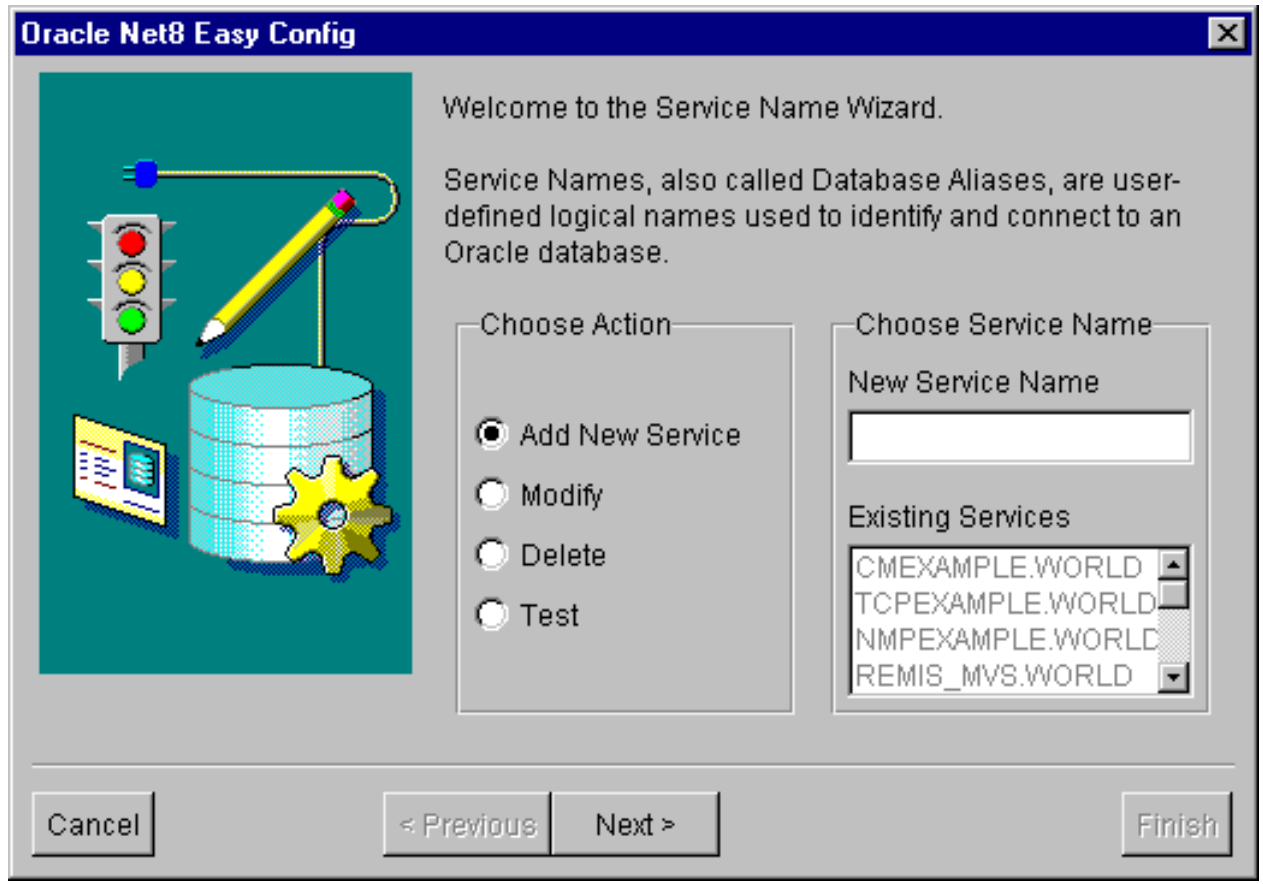

Select Add New Service.

Choose a name for your service. 


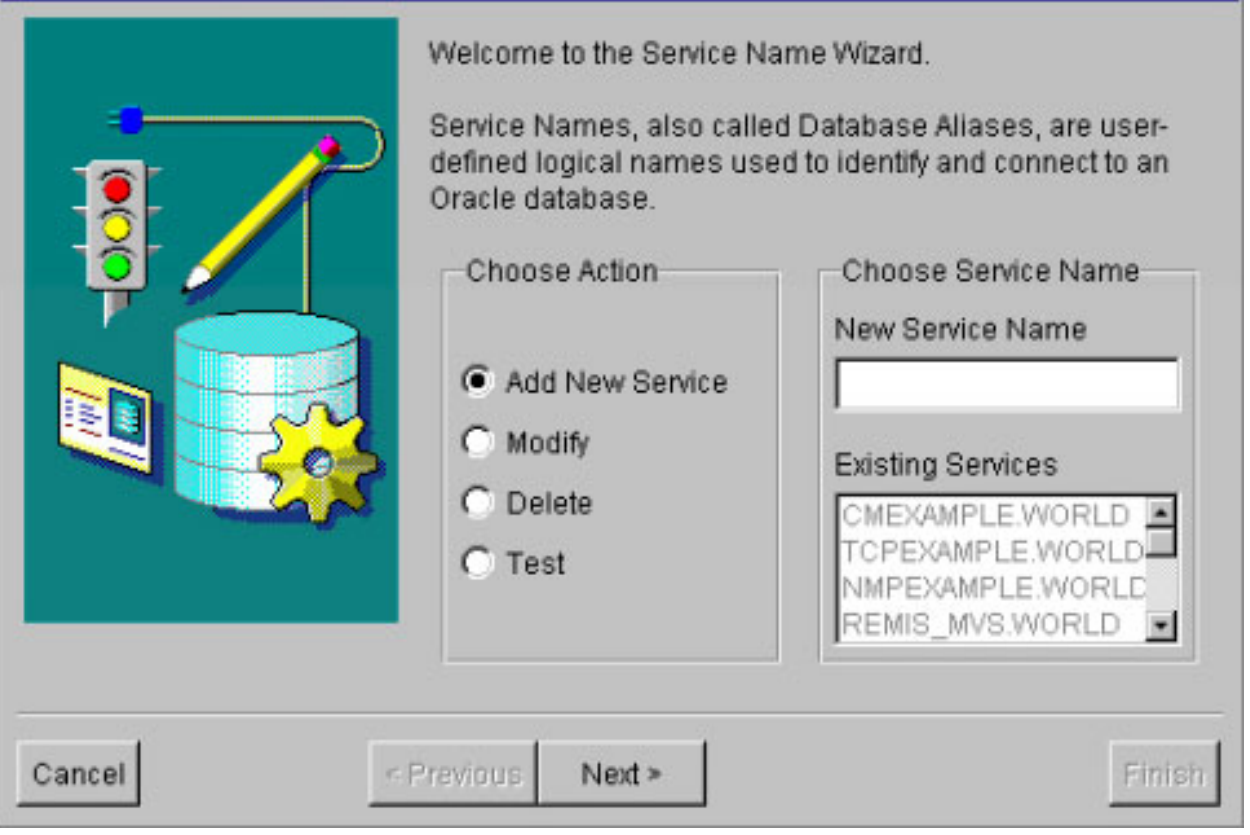

Click the Next button.

Make sure TCP/IP (Internet Protocol) is selected.

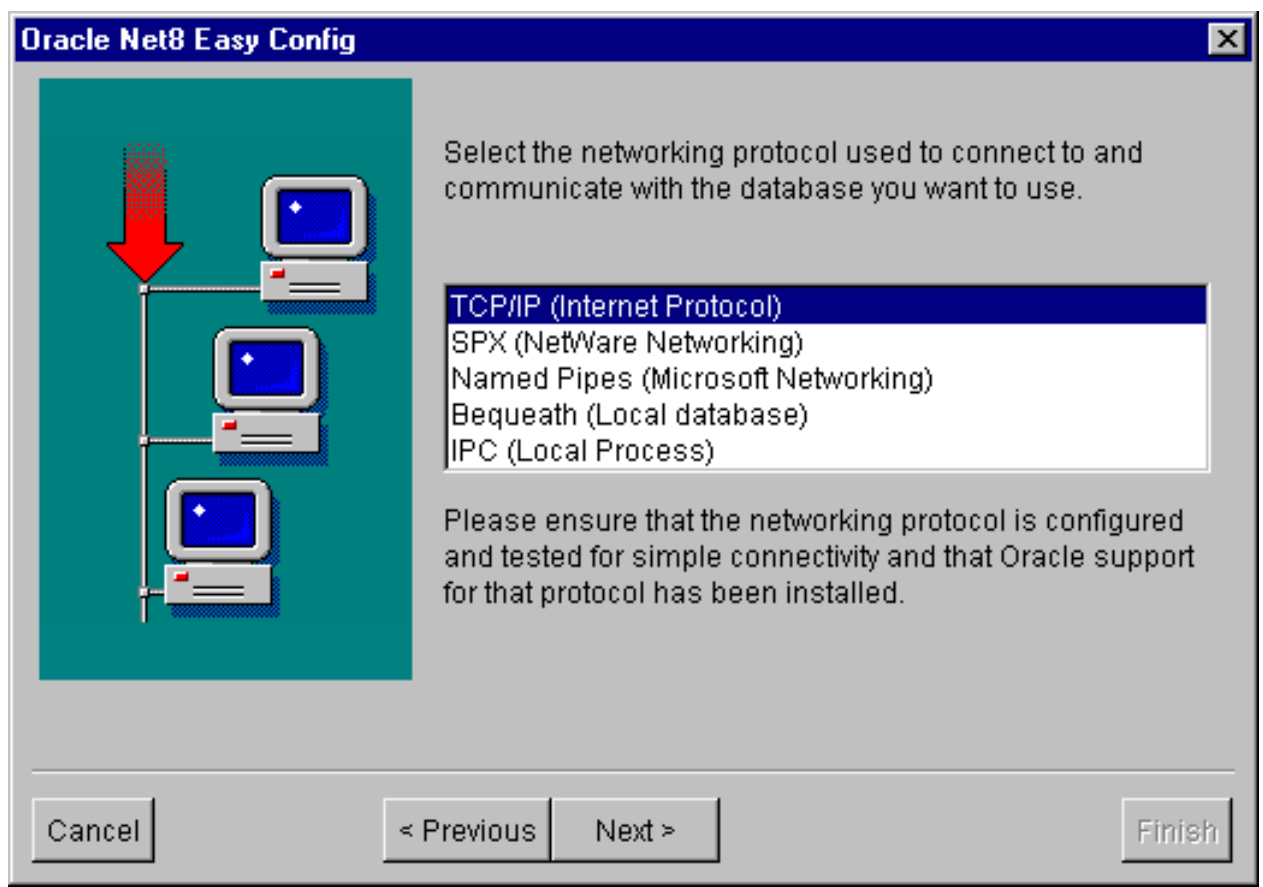

Click Next. 
Enter the IP address of the server to which you wish to connect. Leave the Port number at the default value of 1521 .

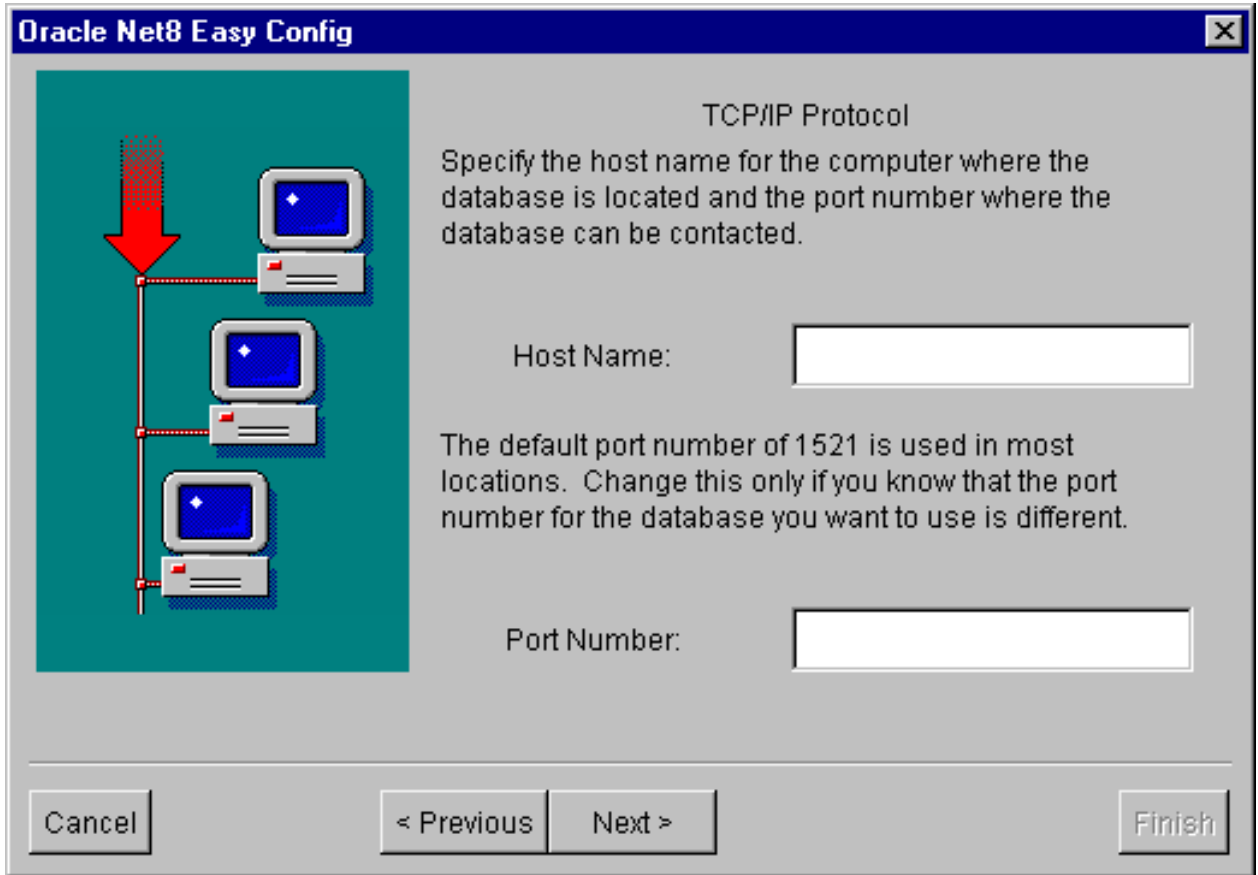

Click the Next button.

Enter the Database SID that is being used on the Oracle server you wish to connect to.

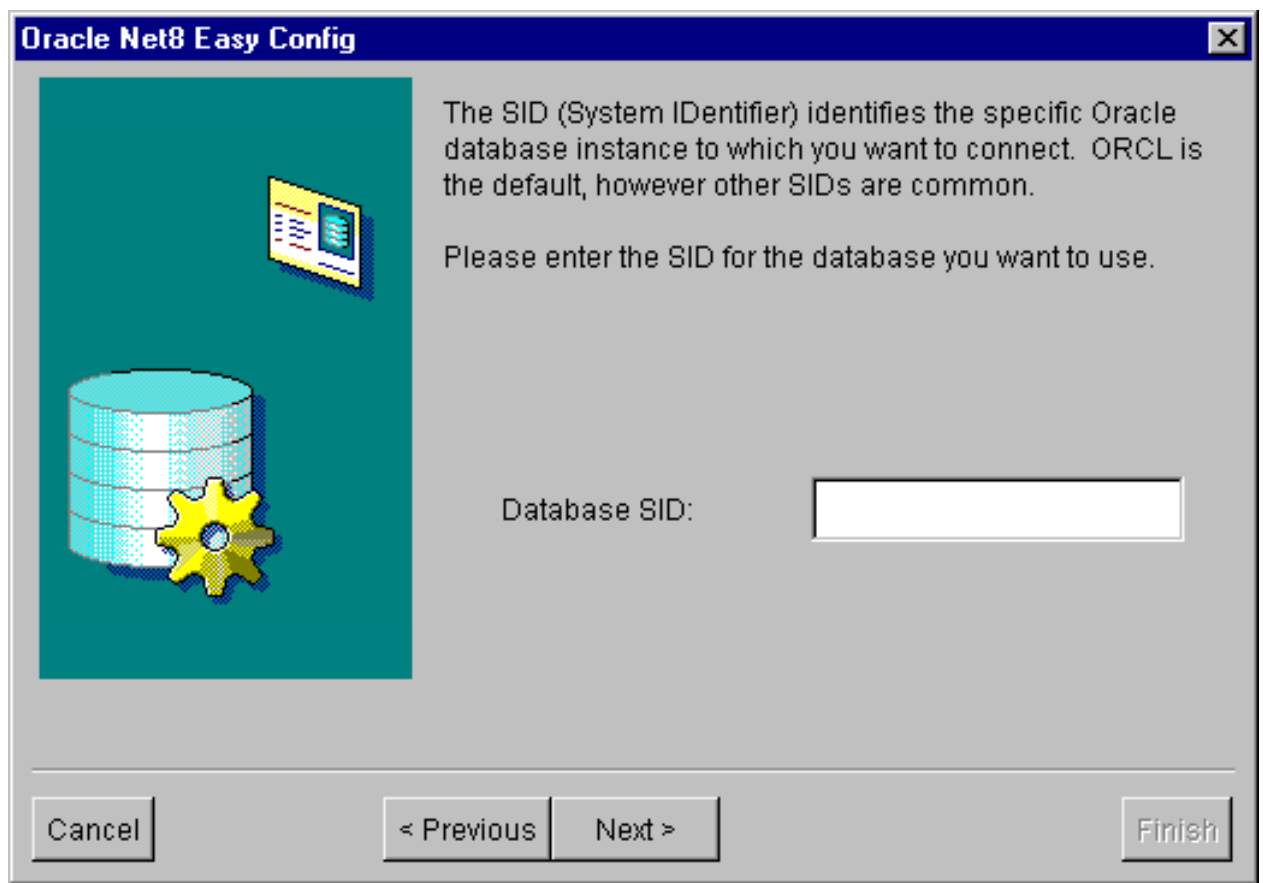

Click the Next button. 


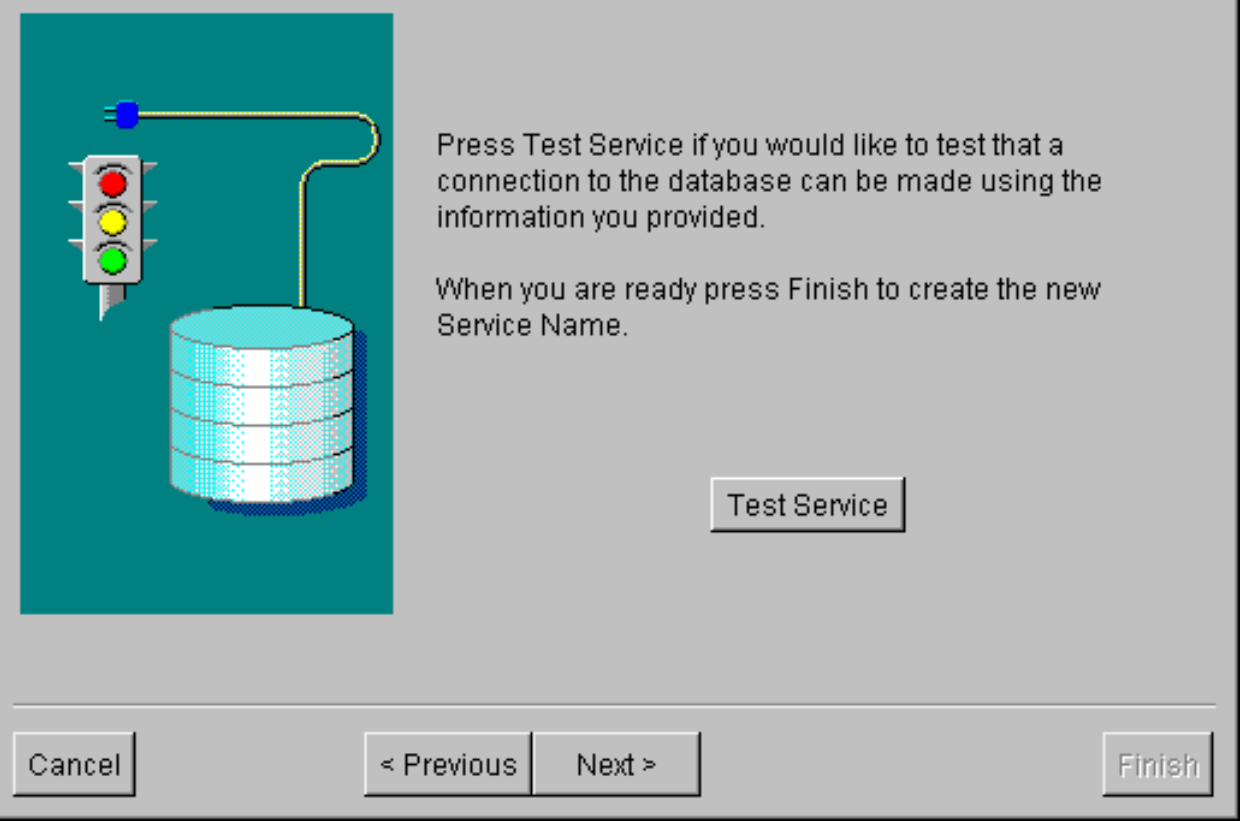

Click the Test Service button to test your connection to the Oracle server.

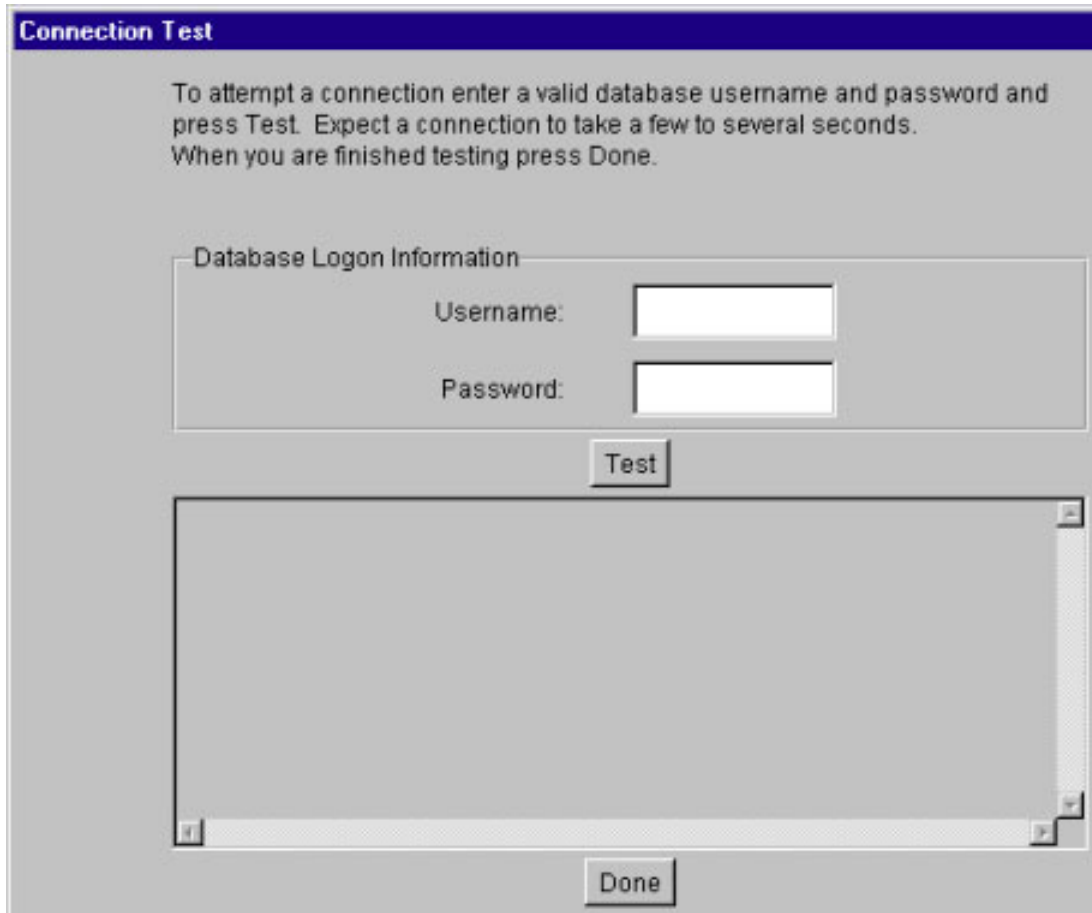

Enter an appropriate Username and Password for the database you are connecting to and click the Test button. You should get the following result: 
To attempt a connection enter a valid database usemame and password and press Test. Expect a connection to take a few to several seconds.

When you are finished testing press Done.
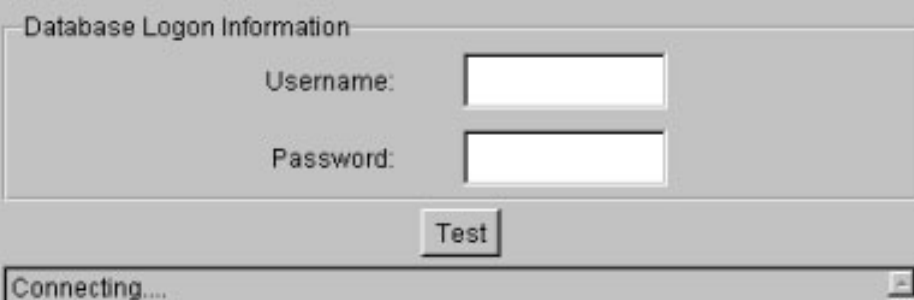

The connection test was successful.

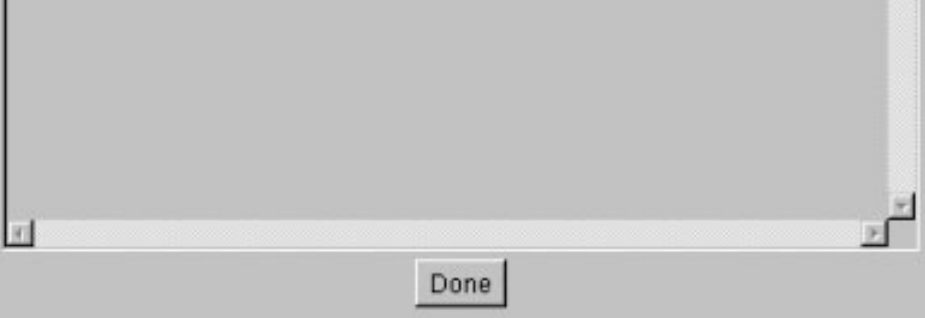

If so, click the Done button.

\section{Oracle Net8 Easy Config}

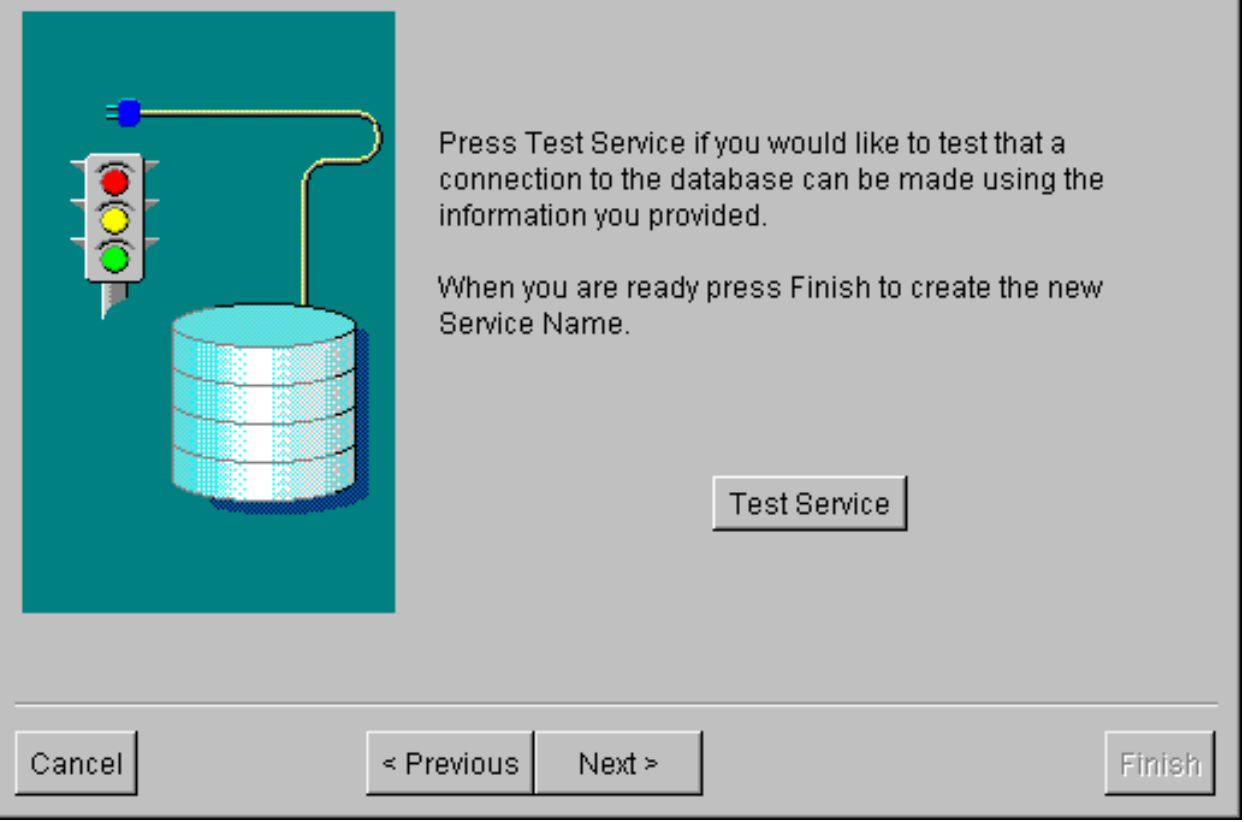

Now click the Next button. 


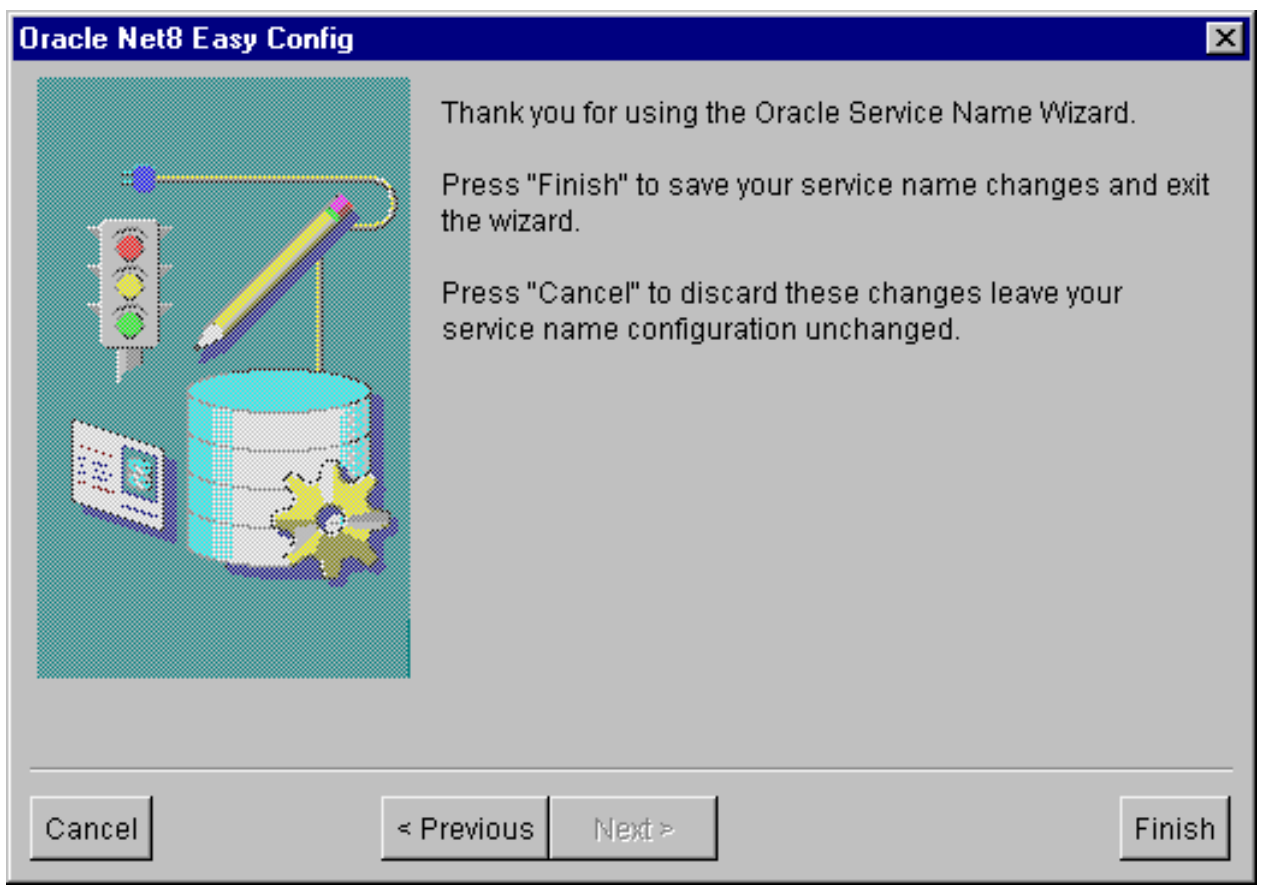

Now you are ready to enter the Windows Control Panel and set up your ODBC connection environment using the service you just created.

\section{Step 2: Create an Open Database Connection (ODBC) Data Source to the REMIS Oracle Database}

1. From the Start menu, select Settings and Control Panel.

2. Double-click the ODBC Data Sources icon.

3. Select the System DSN tab. 


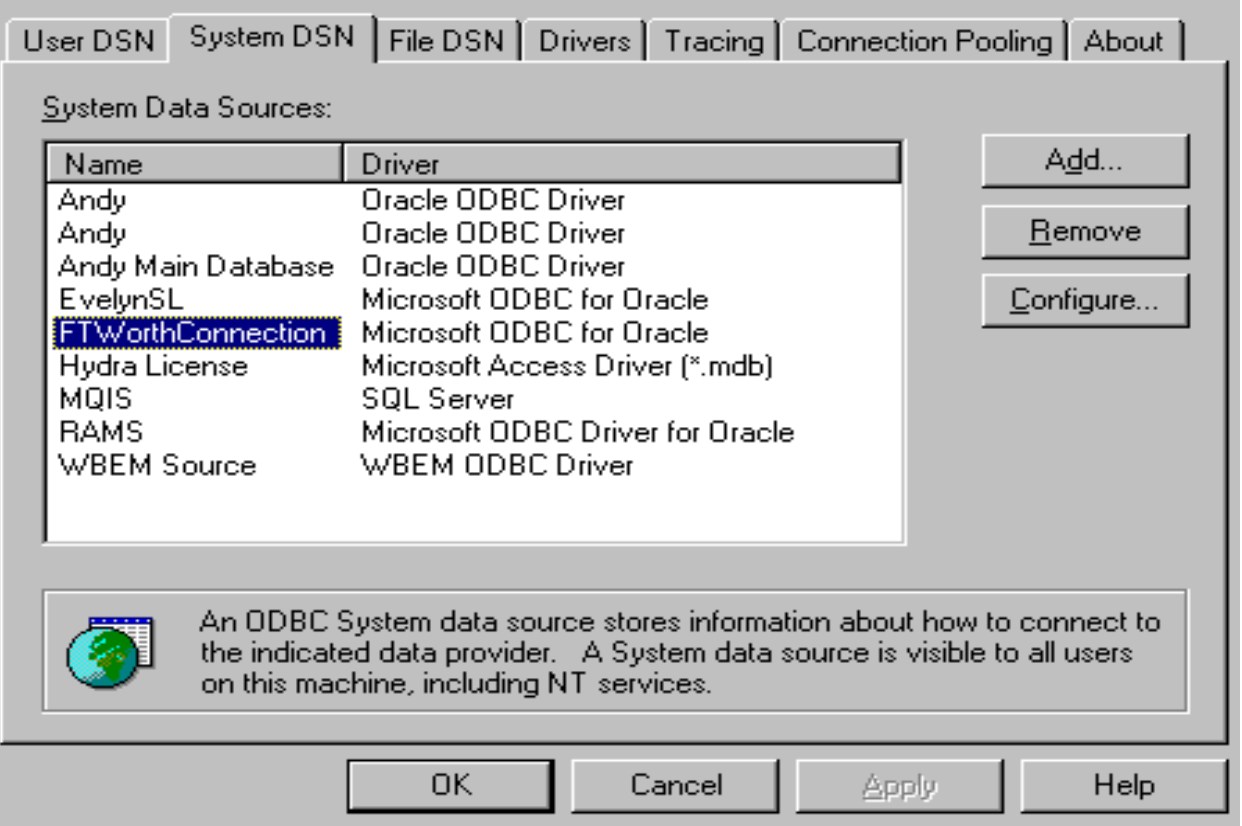

4. Press the Add button.

5. Select the Microsoft ODBC for Oracle driver and press Finish.

6. Enter the desired connection name in the text box beside Data Source Name. Press the Tab key to move to the next entry box. Enter the description of the connection, the user name, and the server where the Oracle tables reside. Select $O K$ when finished.

\begin{tabular}{|c|c|c|}
\hline \multicolumn{3}{|c|}{ Microsoft ODBC for Oracle Setup } \\
\hline Data Source Name: & REMIS & OK \\
\hline Description: & REMIS database connection & Cancel \\
\hline Unser Name: & remis_guest & Help \\
\hline Server: & orcl & Options $>>$ \\
\hline
\end{tabular}

7. Press $O K$ to exit the ODBC Administrator. 


\section{Step 3: Add the Cadastre Real Estate GIS Tool to the Toolbar}

This step can be implemented in ArcCatalog or ArcMap. Follow the steps listed below for the preferred option. If ArcMap is used, you will have the option to save the tool either for a specific file or globally (in the normal.mxt template), meaning that every file loaded or every new file created will have the tool accessible. If ArcCatalog is used, the tool will be saved automatically in the normal.gxt file.

\section{Using ArcCatalog}

1. Start ArcCatalog.

2. Select Tools menu.

3. Go to Customize, Commands, and Add from file.

4. Select the library file REMISGeoDB.dll.

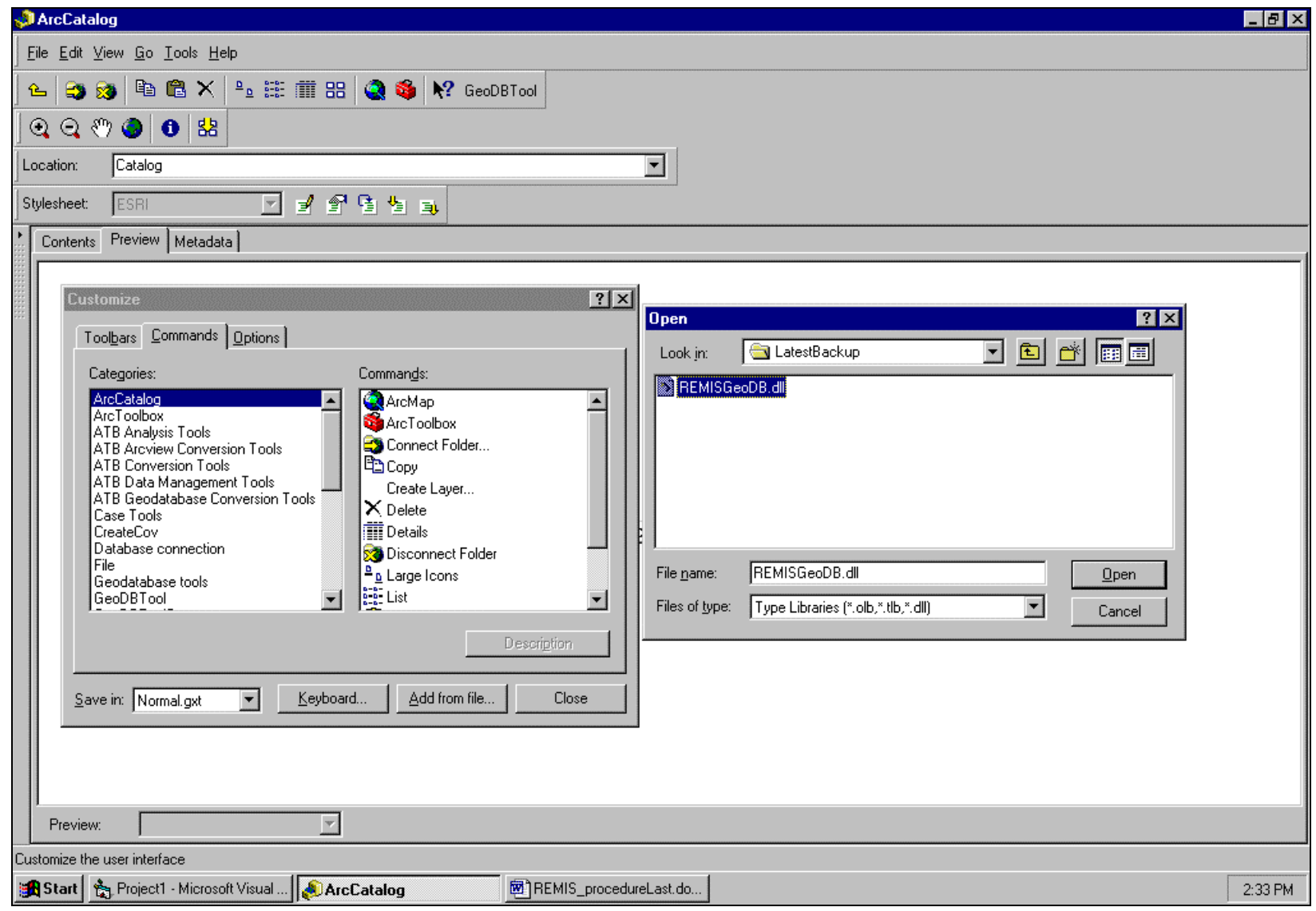


5. An Added Objects box will appear with the REGeoClass listed. Press the $O K$ button.

6. In the Commands tab, choose GeoDBToolCategory from the Categories list.

7. Drag the GeoDBTool from the Commands window to the toolbar.

8. Close the Customize window.

\section{Using ArcMap}

1. Start ArcMap.

2. Select Tools menu.

3. Go to Customize, Commands, and Add from file.

4. At the bottom of the screen, indicate if you want to add the tool to the current opened file or to the general template (normal.mxt).

5. Select the library file REMISGeoDB.dll. 


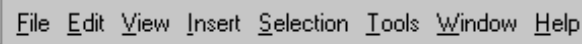

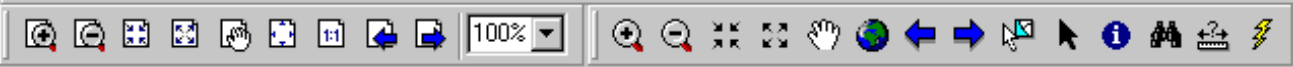

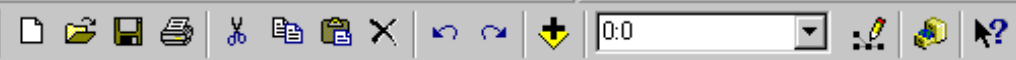

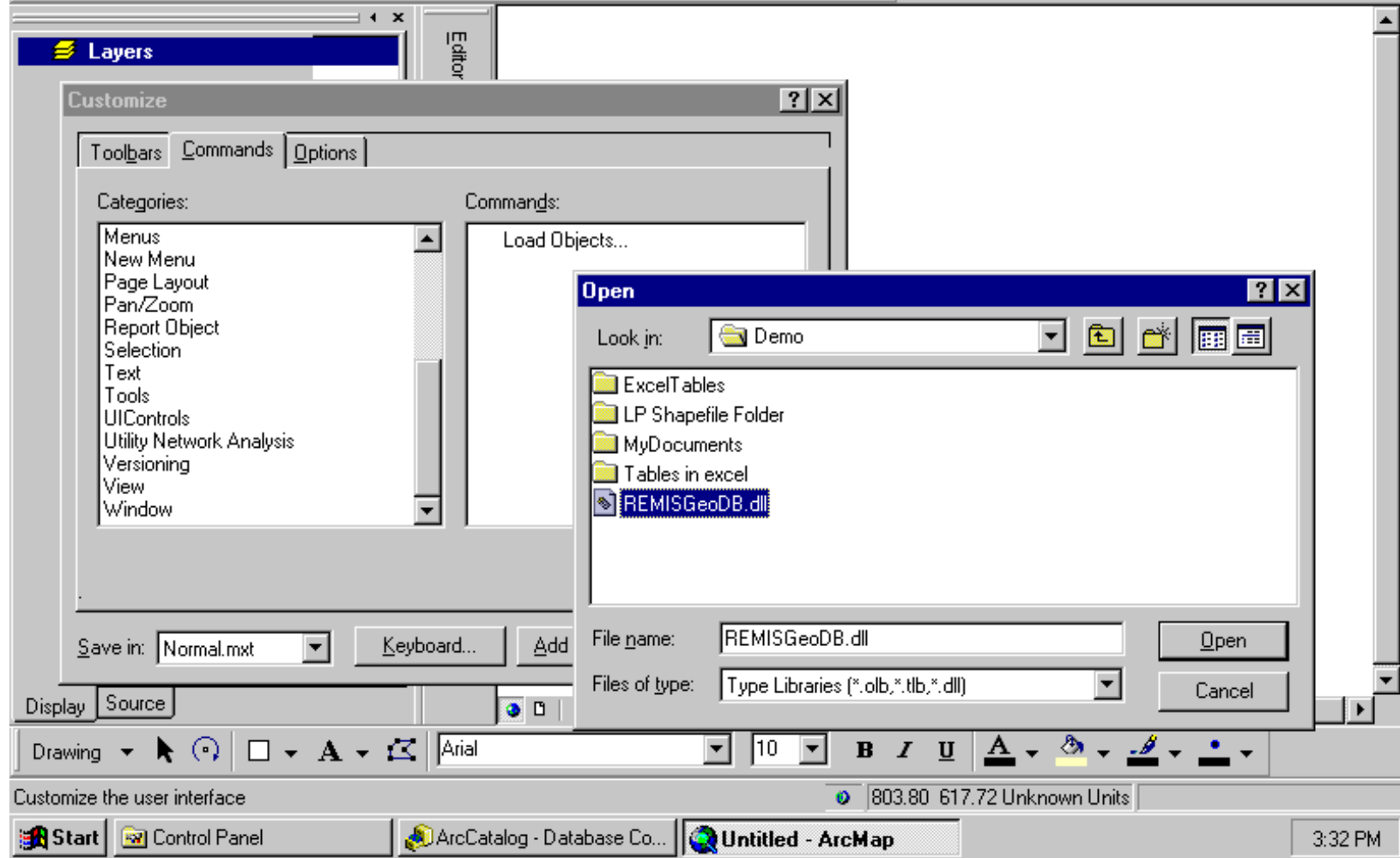

6. An Added Objects box will appear with the REGeoClass listed. Press the $O K$ button.

7. In the Commands tab, choose GeoDBToolCategory from the Categories list.

8. Drag the GeoDBTool from the Commands window to the toolbar.

9. Close the Customize window.

\section{Step 4: Initialize a Personal Geodatabase}

1. Start ArcCatalog.

2. Create a new folder for the REMIS project.

(a) Right click in the Catalog option.

(b) Select the option Connect Folder....

(c) Select the drive where the folder will be created. 
(d) Right click on the drive folder just created and right click on it to create a new folder.

3. Right click on the new folder and click on New and Personal Geodatabase to create a personal geodatabase.

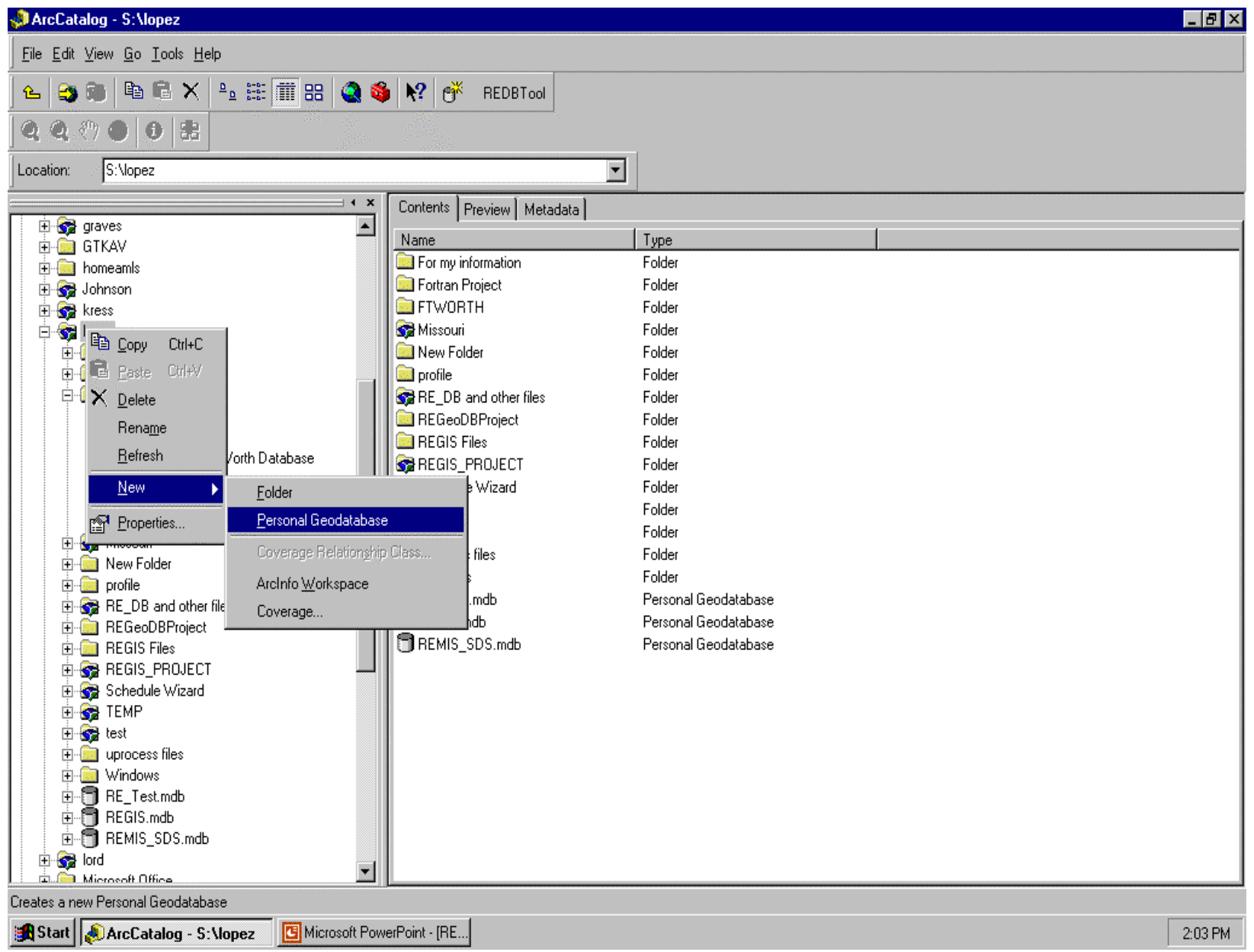

4. Type in the name of the personal geodatabase. The file extension . $m d b$ will be added automatically.

\section{Step 5: Creating Cadastre Tables, Domains, and Relationships}

1. Open ArcCatalog or ArcMap.

2. Click on the command Create Cadastre Tables, domains, and relationships. This creates the Cadastre Feature Dataset that contain the five cadastre tables: cdrelacq, cdrelout, cdrelbnd, cdrelenc, and cdreldsp. The tables are created in 
MS Access 2000 and can be seen from ArcCatalog. In ArcMap, to view the feature datasets and their contents, click the feature datasets from the ArcCatalog geodatabase and drag them (one by one) into ArcMap. You will not be able to click and drag the whole personal geodatabase at once into ArcMap, only the feature datasets (one by one) and other tables (one by one) that exist in the personal geodatabase.

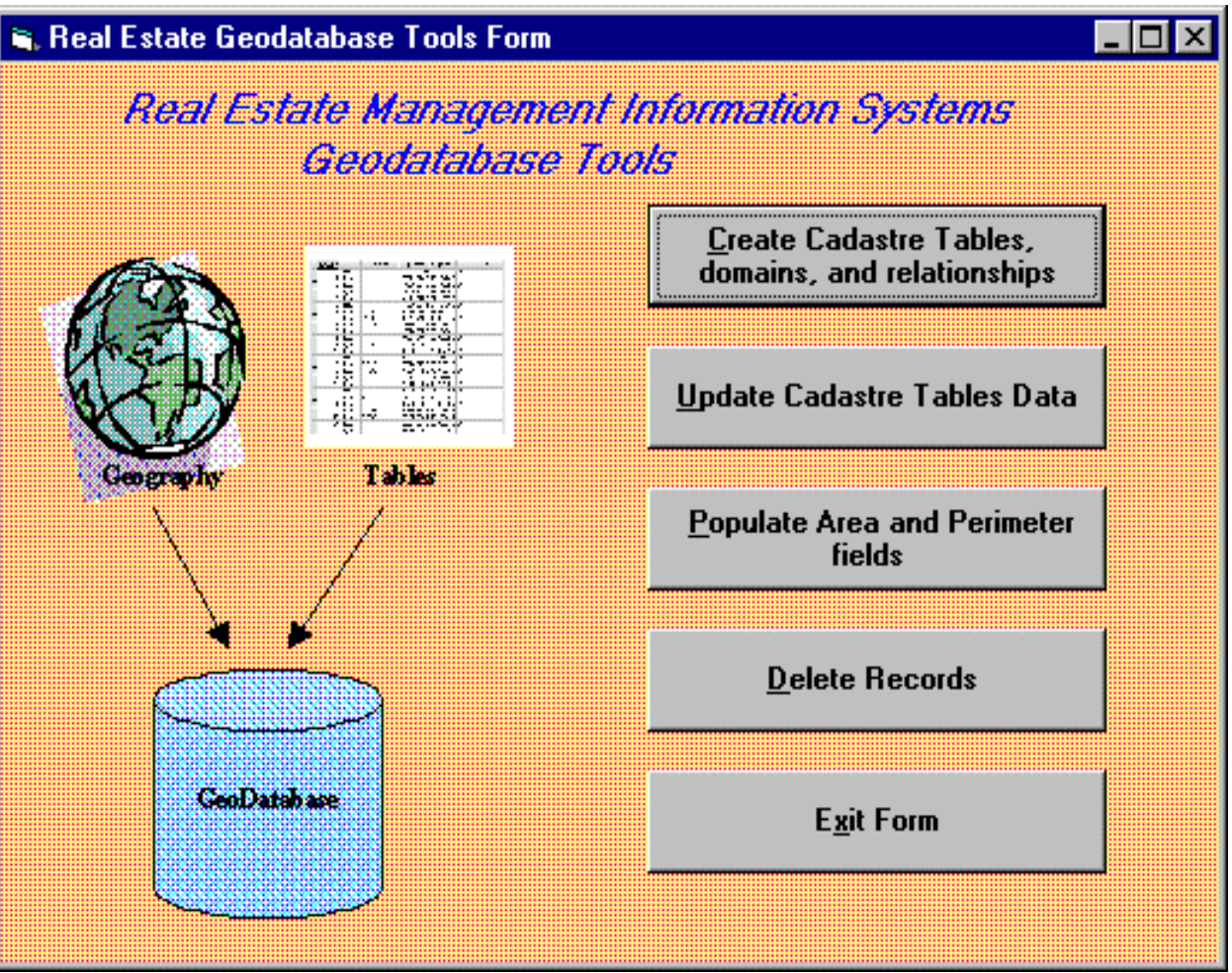

3. After you click on the Create Cadastre Tables, domains, and relationships command, another form appears. It allows you to enter the location of the personal geodatabase. 


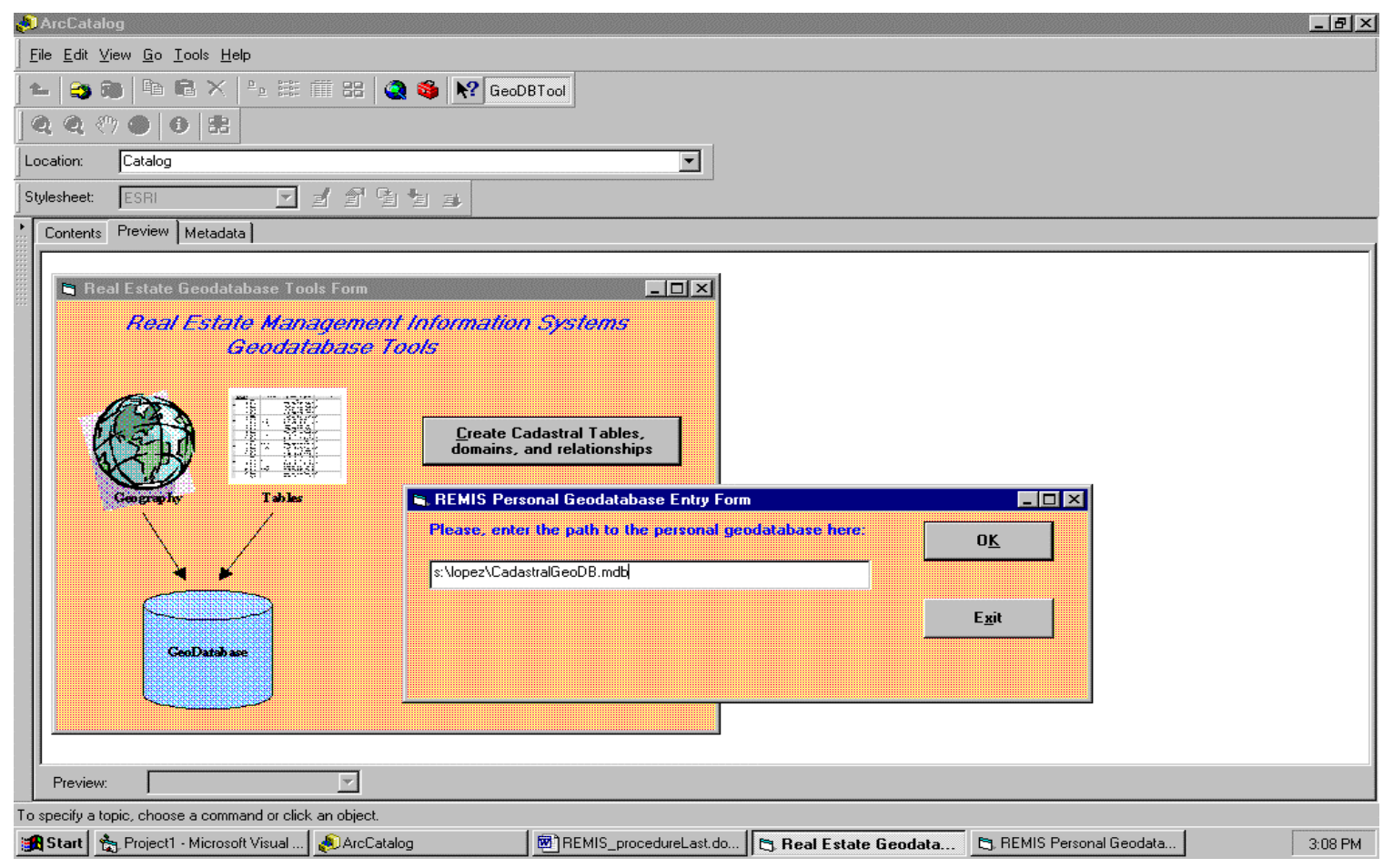

4. Once you press the $O K$ button, a List Box appears letting you know what the command is doing.

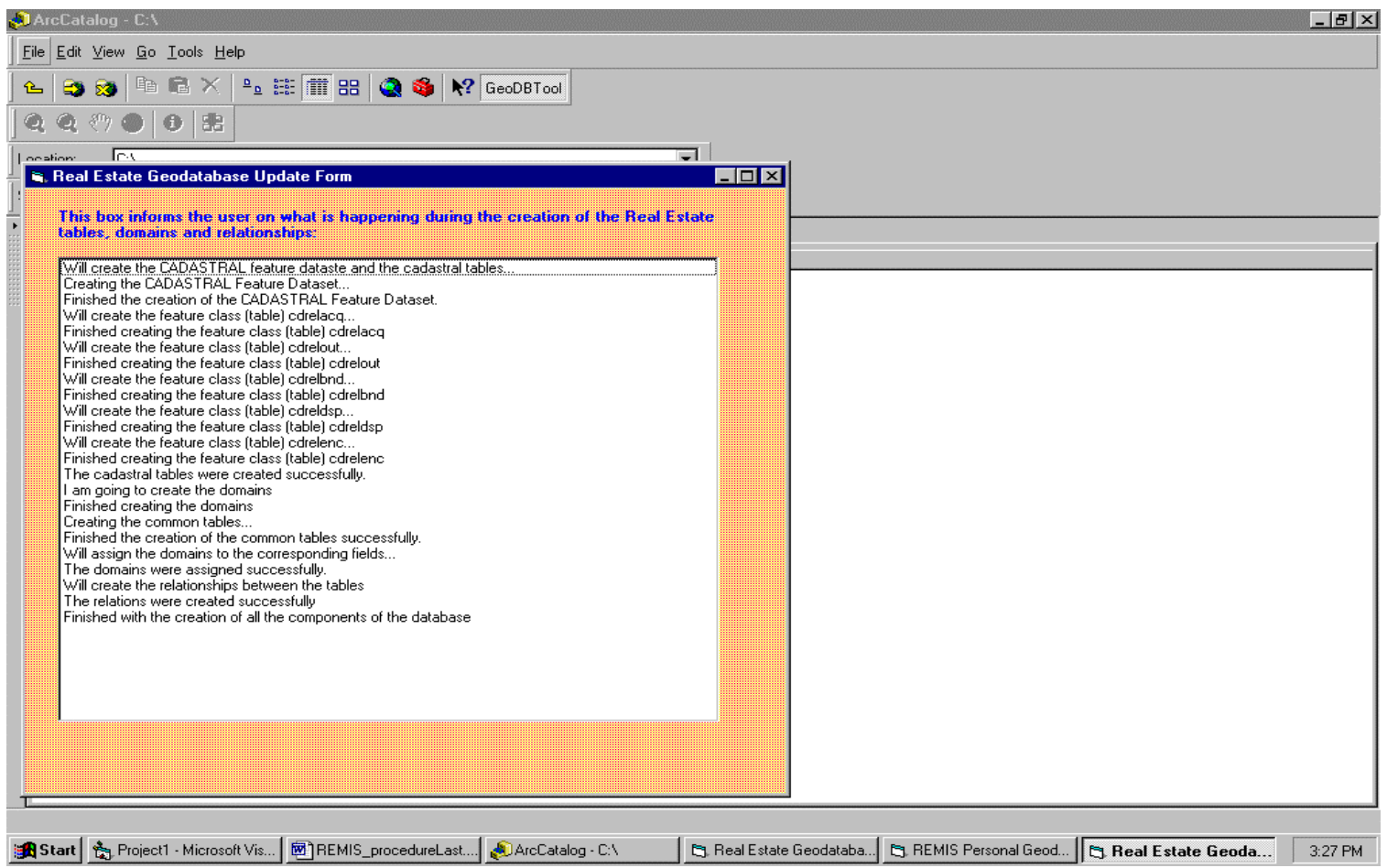


5. After the command is finished, close the forms (except the form with all the command buttons, the Geodatabase Tools Form) and compact the database by right-clicking the geodatabase and choosing the Compact Database option.

Note: The Geodatabase Tools Form will be minimized if you click on any other part of ArcCatalog or ArcMap. If this happens, just maximize the form if you need to perform other commands from it.

6. Refresh the database by clicking on the geodatabase and then pressing the $F 5$ key in ArcCatalog.

\section{Step 6: Populate the Cadastre Geodatabase with GIS Geospatial Data}

\section{A. $X$ and $Y$ Domains}

The spatial domain is best described as the allowable coordinate range for $\mathrm{x}, \mathrm{y}$ coordinates, $\mathrm{m}$ (measure) values, and $\mathrm{z}$ values. The precision describes the number of system units per one unit of measure. A spatial reference with a precision of 1 will store integer values, while a precision of 1,000 will store three decimal places. Once the spatial reference for a feature dataset or stand-alone feature class has been set, only the coordinate system can be modified; the spatial domain is fixed.

If adding a new coordinate outside a geodatabase $\mathrm{x}, \mathrm{y}$ domain in ArcMap returns the error:

\section{"The Create Feature task could not be completed.} The coordinates or measures are out of bound."

the cause is that coordinates of the added feature are beyond the extents of the feature class x,y domain. Geodatabase feature coordinates must fall within the feature class $\mathrm{x}, \mathrm{y}$ domain extent. The $\mathrm{x}, \mathrm{y}$ domain is set when the data set or standalone feature class is created. It cannot be updated after creation.

\section{Solution}

1. Right-click the problem feature class from ArcCatalog and click Export and Geodatabase to Geodatabase.

2. Navigate to the output Geodatabase location and type the name of the new feature class. 


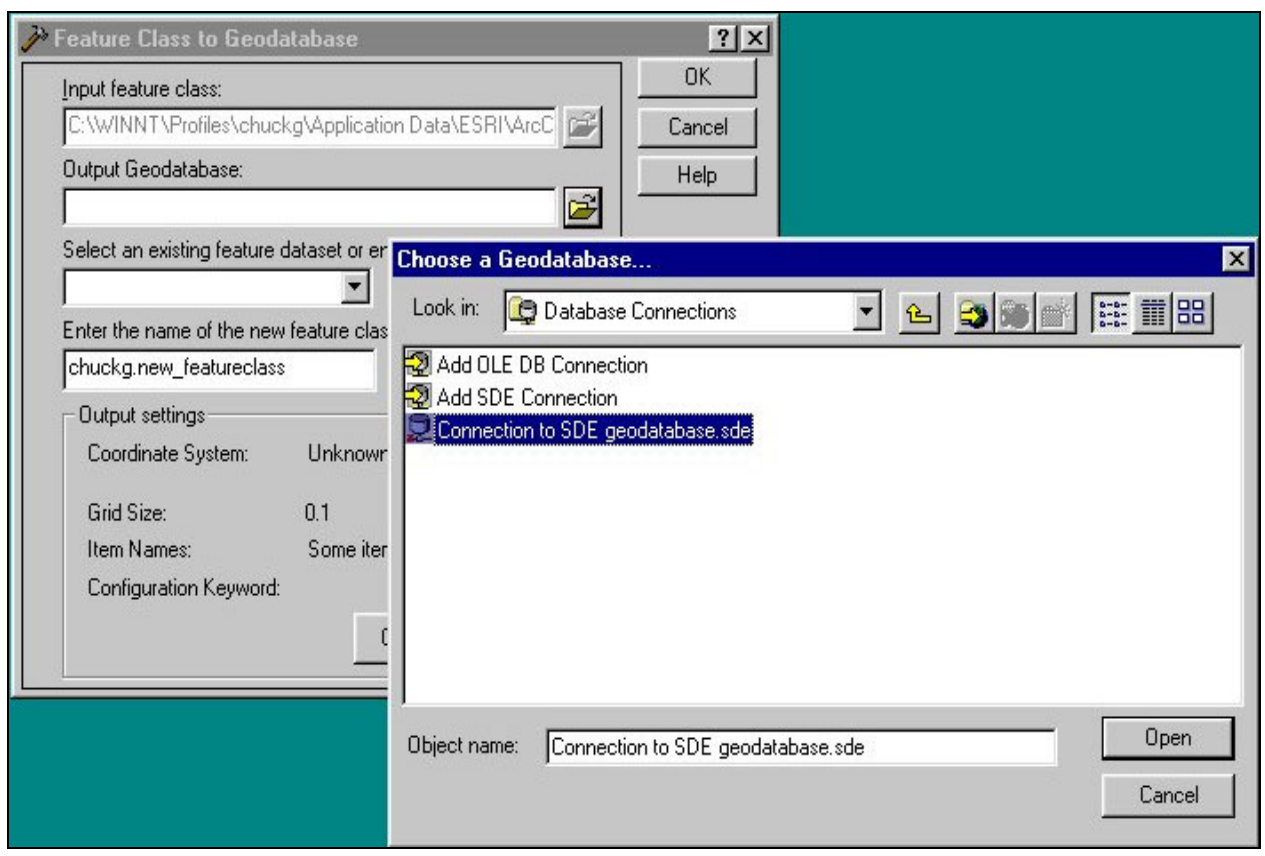

3. Click Change Settings, the Spatial Ref tab and Change.

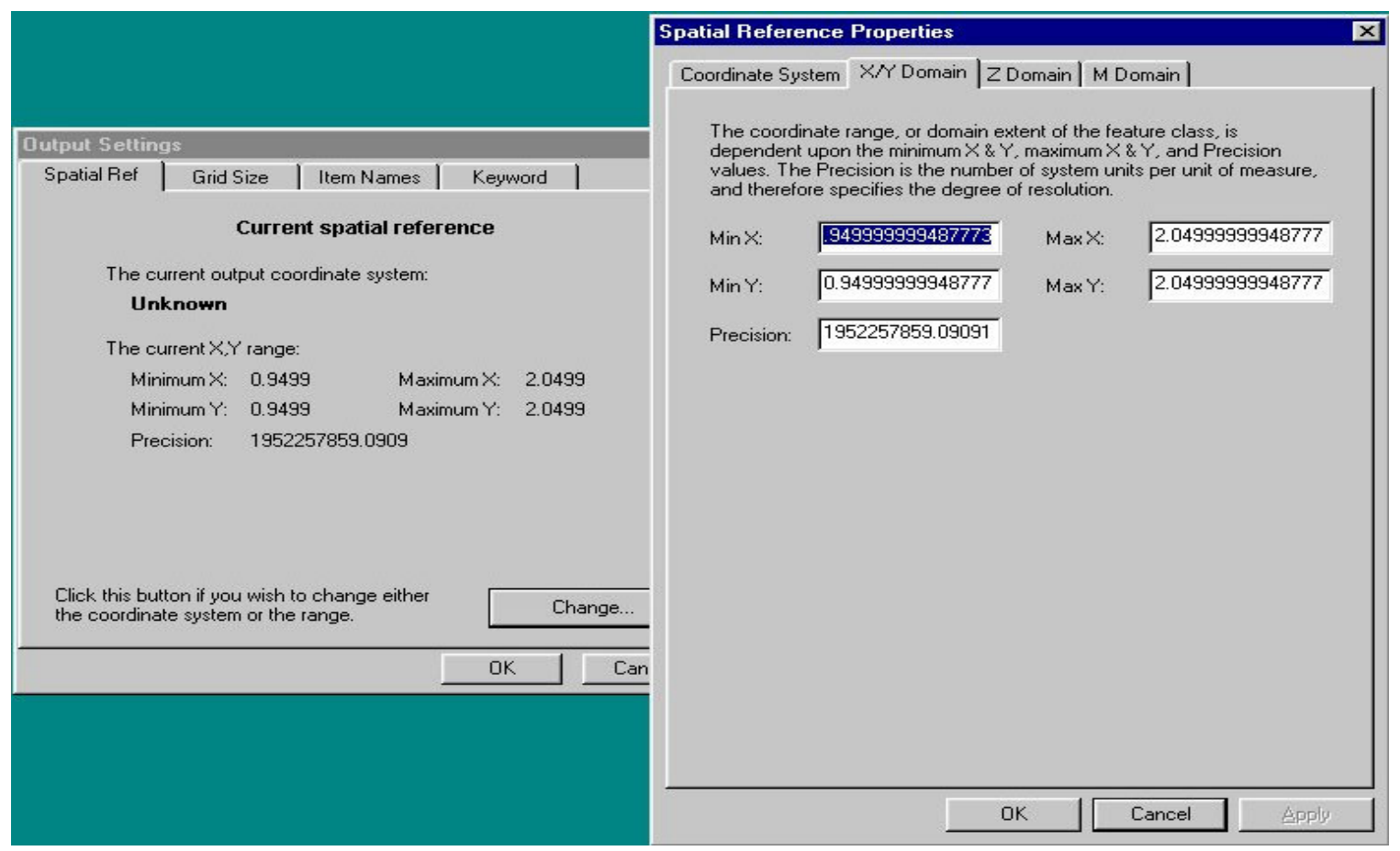

4. Click the $X / Y$ Domain tab and update the extents to accommodate the new data you wish to add.

5. Click $O K$ on the three dialog boxes to initiate the export. 
6. If using an SDE Geodatabase, right-click the new feature class to register it as versioned before returning to ArcMap to edit.

7. Verify the new feature class extents in ArcMap by right-clicking on Feature Class, Choose Properties, and the Source tab.

All feature classes in a feature data set possess the $\mathrm{X} / \mathrm{Y}$ domain of the feature data set. If your original feature class is in a feature data set, the new feature class cannot reside in the original feature data set. It must be created as a stand-alone feature class or a feature class in a feature data set with extents that go far enough to encompass the new coordinates.

\section{B. Coordinate Systems}

There are two types of coordinate systems: geographic and projected. Geographic coordinate systems use latitude and longitude coordinates on a spherical model of the earth's surface. Projected coordinate systems use a mathematical conversion to transform latitude and longitude coordinates that fall on the earth's threedimensional surface to a two-dimensional surface.

To choose a coordinate system in ArcCatalog:

1. Start ArcCatalog.

2. Choose the coordinate system by doing the following steps:

(a) Right-click on the feature data set.

(b) Select the option Properties.

(c) Click Edit.

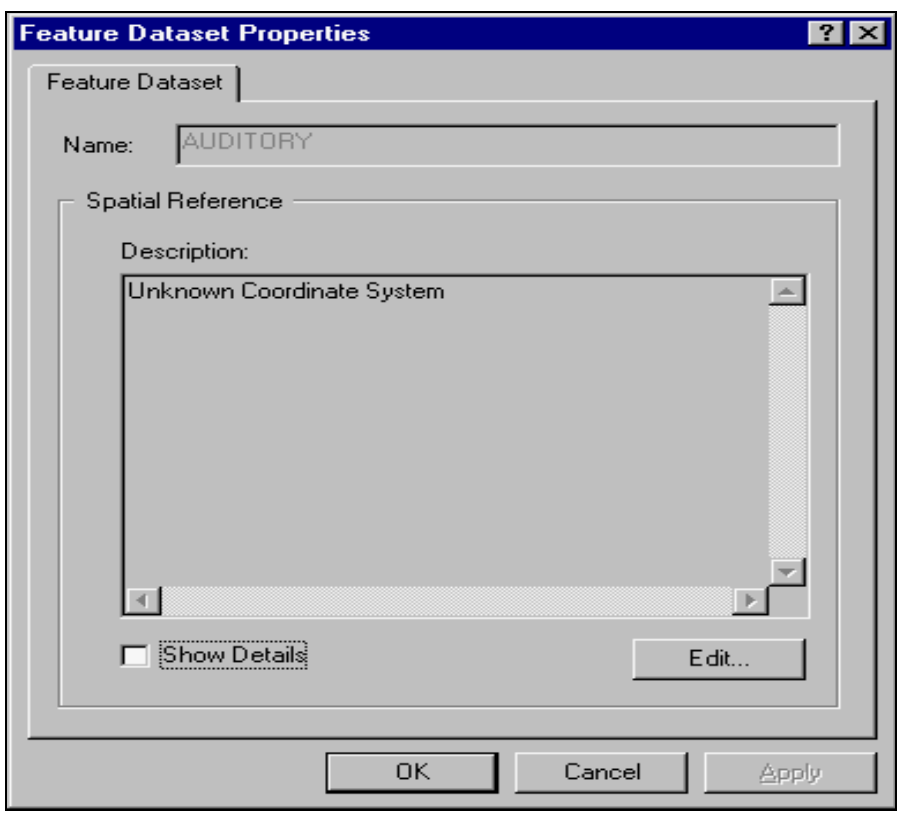


(d) Click the Select button to select a predefined coordinate system or select the New button to create a new coordinate system. Navigate to the spatial reference you want to use. Click the $A d d$ button.

(e) After the addition is done, click the Apply button.

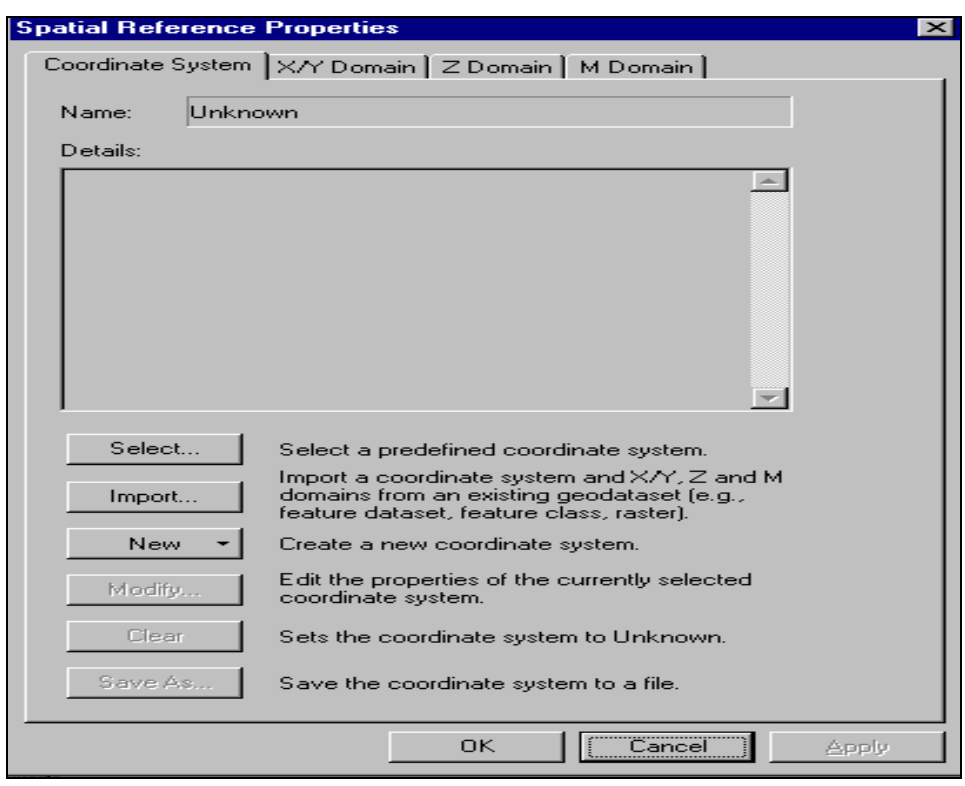

(f) To see the details of your new dataset's spatial reference, check Show Details.

(g) Click Apply again and the $O K$ button.

(h) Refresh the geodatabase by clicking on the geodatabase and press the F5 key.

\section{Migrating a shapefile and/or coverage to an SDS personal geodatabase}

1. In the ArcCatalog tree, right-click the table or feature class that you want to load data into and click Load Data.

2. Click Next on the introductory panel. 


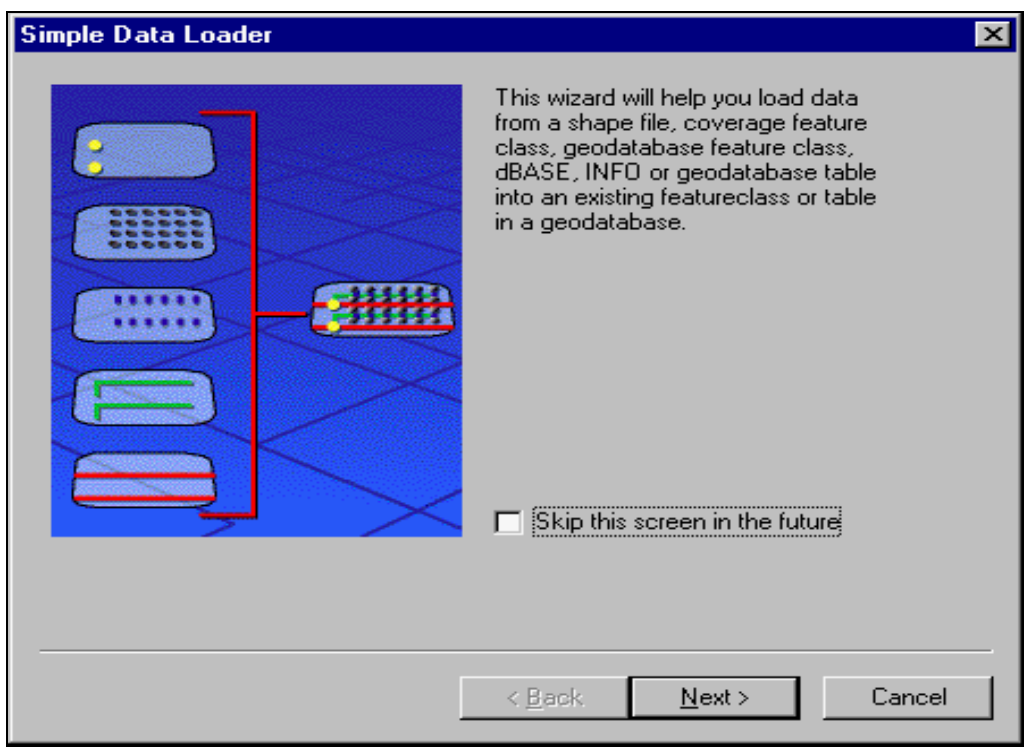

3. Browse to the input feature class or table.

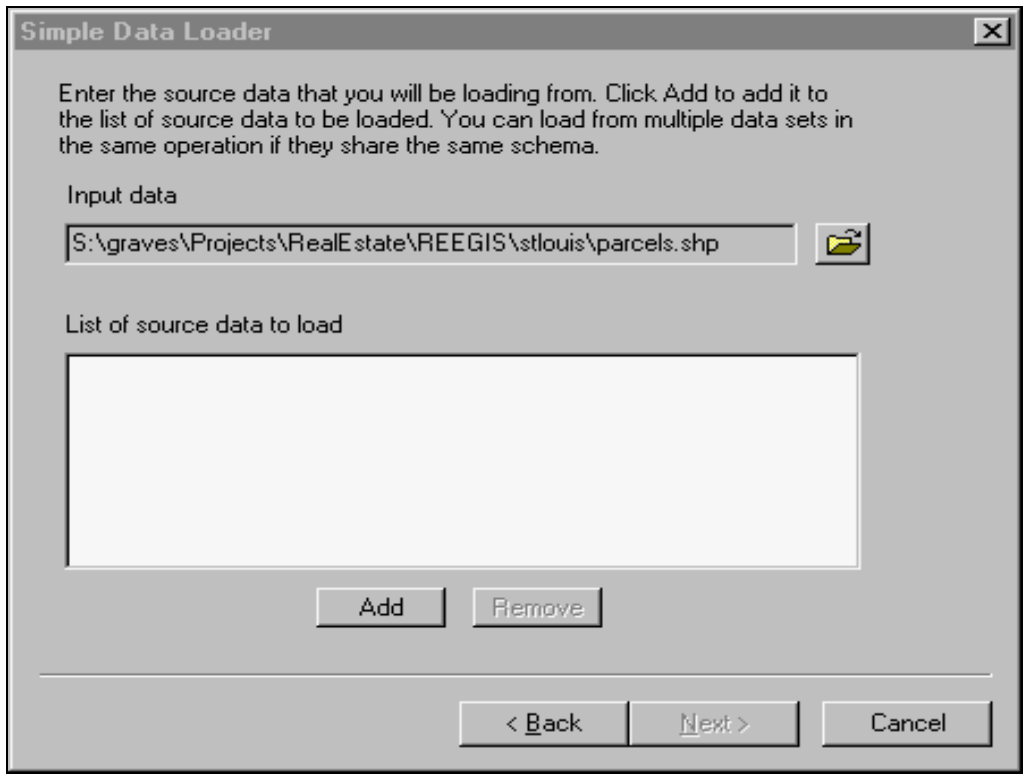

4. Click $A d d$ to add it to the list of source data.

5. Repeat steps 3 and 4 until you have specified all of the source data.

6. Click Next.

7. If you don't want to load data into a specific subtype of the target, click the first option, and then skip to step 10 (ArcInfo and ArcEditor only). 


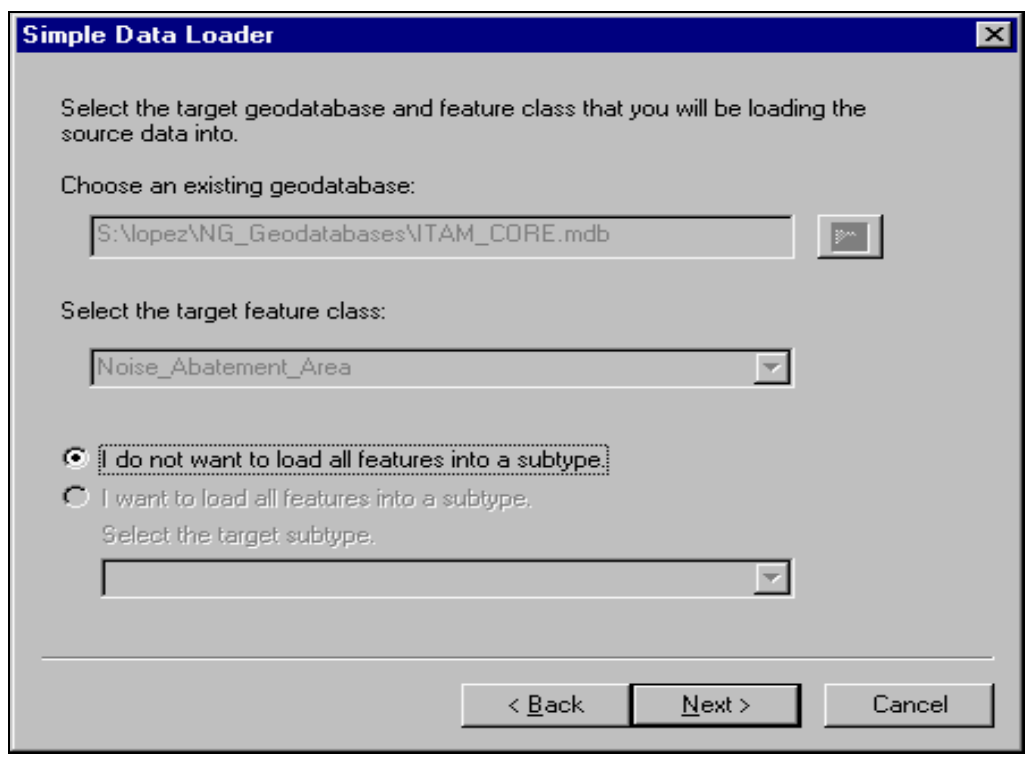

8. If you want to load data into a specific subtype, click the second option (ArcInfo and ArcEditor only).

9. Click the dropdown arrow and click the subtype you want to load the source data into.

\section{Click Next.}

11. To match a source field with a field in the target feature class or table, click the dropdown arrow in the Matching Source Field list and click the field from the source data that you want to match to the target field.

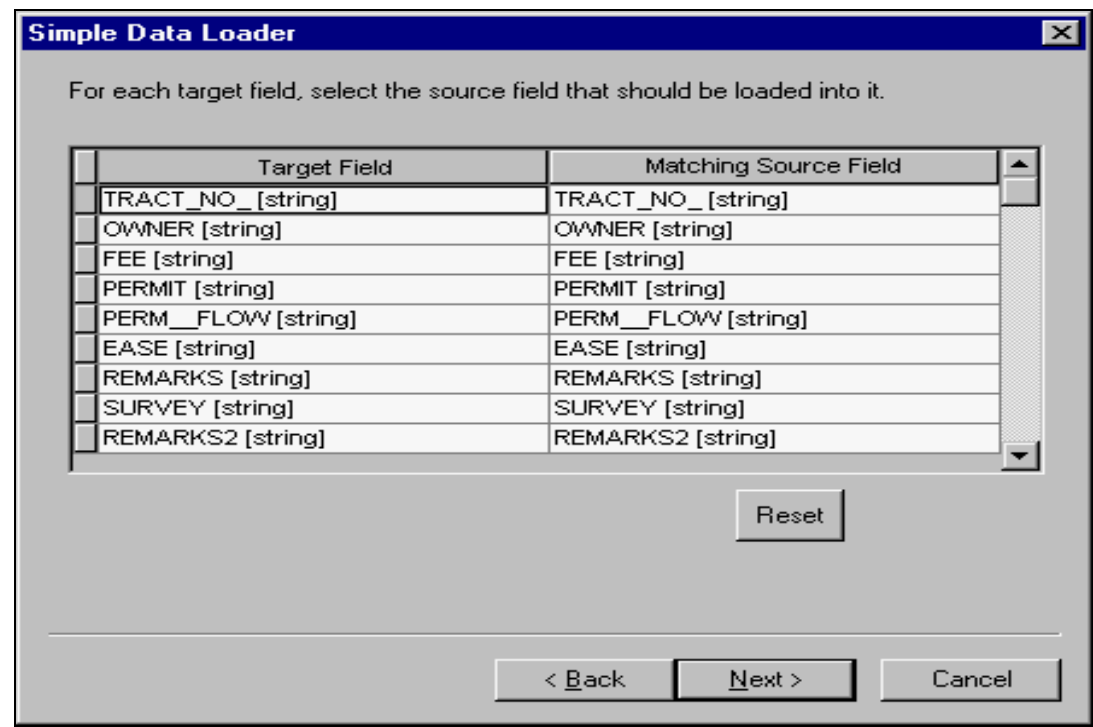

12. Repeat step 11 until you have matched all the fields you want to load from your source data to the target fields. 
13. If you don't want data from a field in the source data to be loaded into the target data, leave the Matching Source Field blank.

\section{Click Next.}

15. If you want to load all of the source data, click the first option and then skip to step 20.

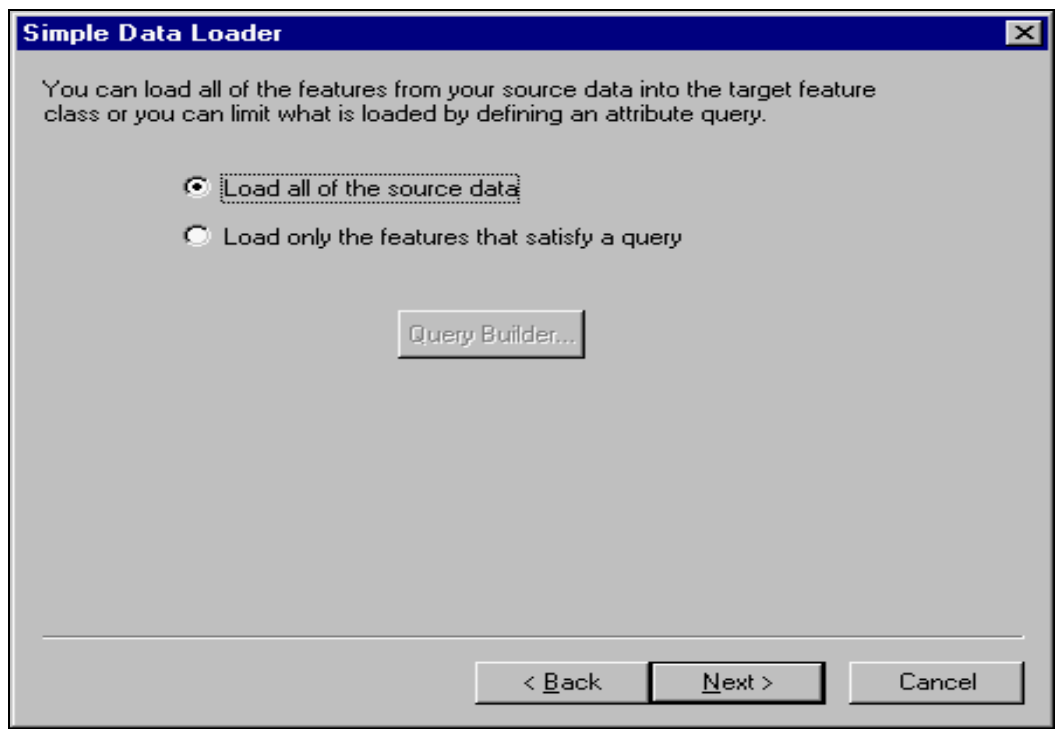

16. If you want to use an attribute query to limit the features from the source data loaded into the target, click the second option.

17. Click Query Builder to open the Query Builder dialog box.

18. Use the Query Builder to create a query to limit the features or rows from the source data that are going to be loaded into the target.

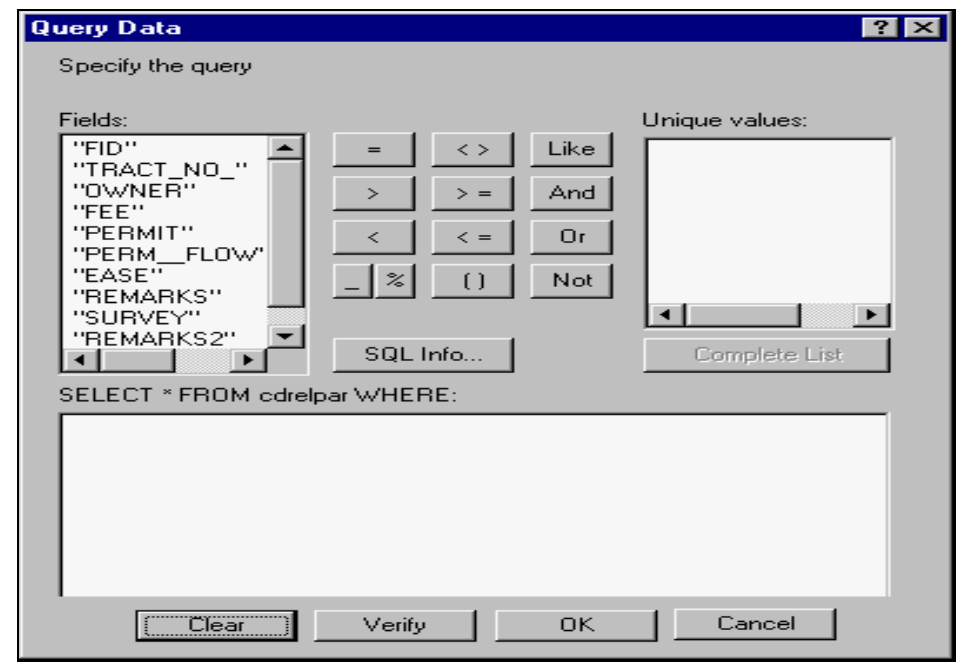

19. Click $O K$. 


\section{Click Next.}

21. Review the options you have specified for loading your data. If you want to change something, you can go back through the wizard by clicking Back.

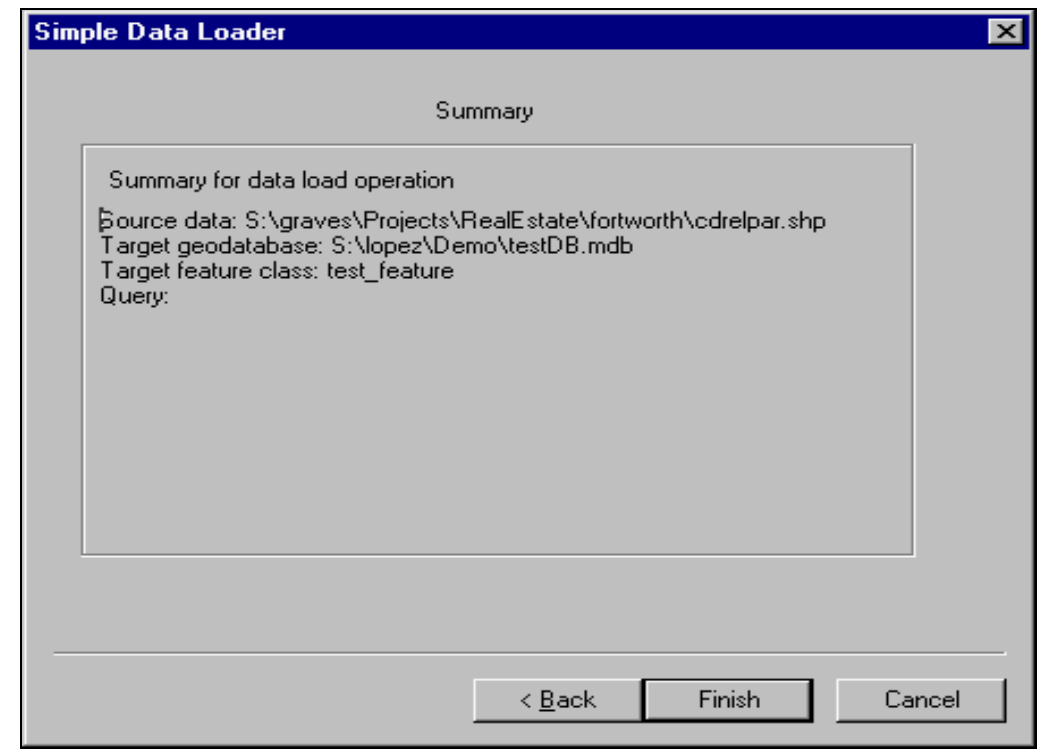

22. When satisfied with your options, click Finish to load your data.

Notes: If you choose to load data into a specific subtype, you won't be able to match a field from the source data to the subtype field in the target data; the subtype field will be automatically populated.

When matching fields, you can browse the source data's field values to help you correctly match the source and target fields.

23. The following fields in each Cadastre table need to be populated for each polygon:

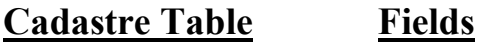
Cdrelacq
PROJ_ID and TRACT_NO
Cdrelbnd
PROJ_ID
Cdreldsp
PROJ_ID and DISP_UNIT
Cdrelenc
PROJ_ID, W_CODE, and ENC_ITEM
Cdrelout
PROJ_ID, CONTRACT_NO, MOD_NUMBER, and OUTTGRANT_STATUS

24. If some of these fields are not populated, you will need to update them manually using ArcMap. To access ArcMap from ArcCatalog, click on the icon in the tool bar that looks like the following: 


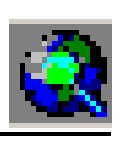

To populate the fields in ArcMap:

a. In ArcCatalog, click on the feature class (tables with polygons) and drag it to the ArcMap grid window. Repeat this step for each one of the feature classes.

$b$. Use the Editor Tool.

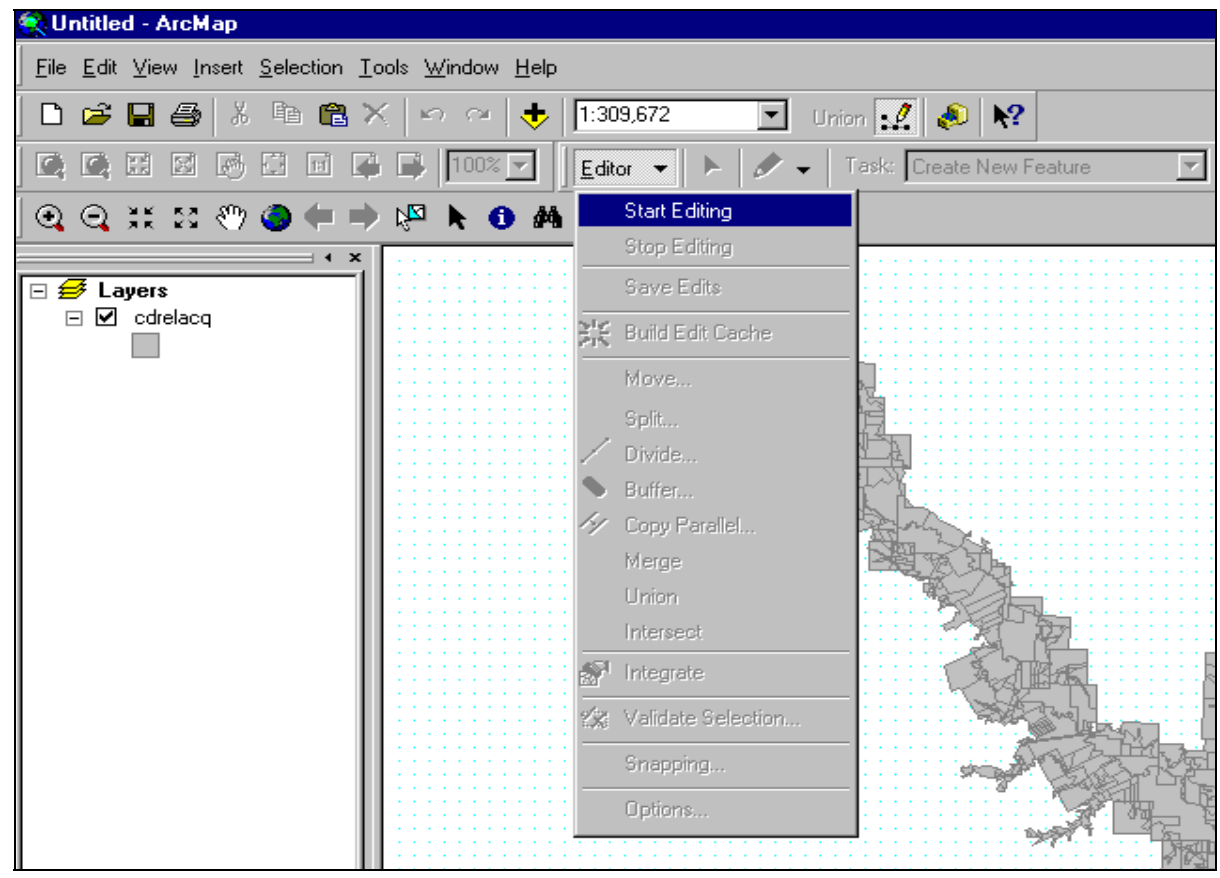

c. Click on Start Editing.

d. Start typing the values for the necessary fields.

e. After editing the fields, choose Save Edits and then Stop Editing in the Editor Tool. You do not have to save the file in ArcMap as long as Save Edits was selected before going back to ArcCatalog.

f. When finished, exit ArcMap and return to ArcCatalog.

g. In ArcCatalog, refresh the database to see the changes done in ArcMap. 


\section{Step 7: Update Cadastre Tables Data}

The command Update Cadastre Tables Data imports the REMIS Oracle Database data to the corresponding fields in the Cadastre tables.

1. The following form appears. You will need to coordinate with the REMIS database administrator at the District to obtain the necessary access information, and the ODBC connection must have been properly configured (as described earlier in this document).

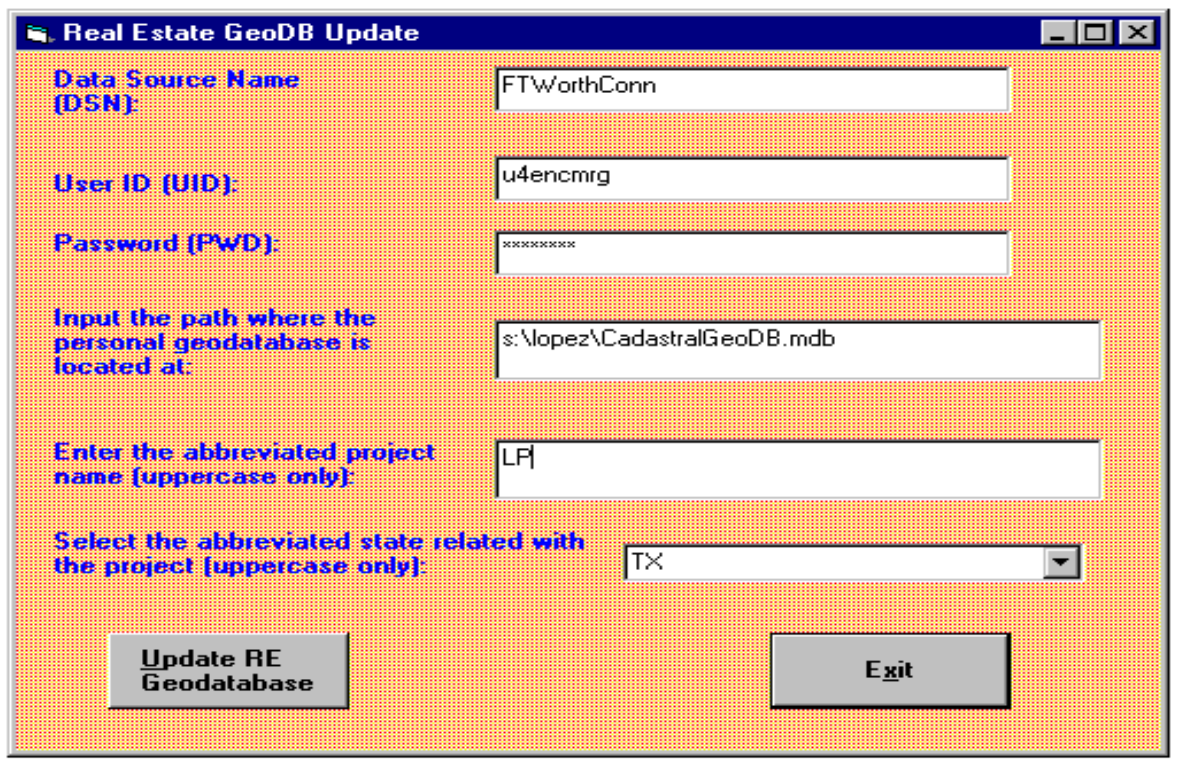

2. Select the Update RE Geodatabase button after the information is entered to start the update of the Cadastre tables.

3. A window will appear informing you which tables are being updated.

4. Refresh the database by clicking on the geodatabase and then pressing the $F 5$ key.

\section{Step 8: Populate Area and Perimeter Fields}

The command Populate Area and Perimeter fields populates the area and perimeter fields of the polygons with feet/square-feet or meters/square-meters units.

1. Select the desired unit of measure for the area and perimeter fields.

2. Press $O K$. When the updating of the fields with the unit is done, a label will appear notifying you that the update is finished. 


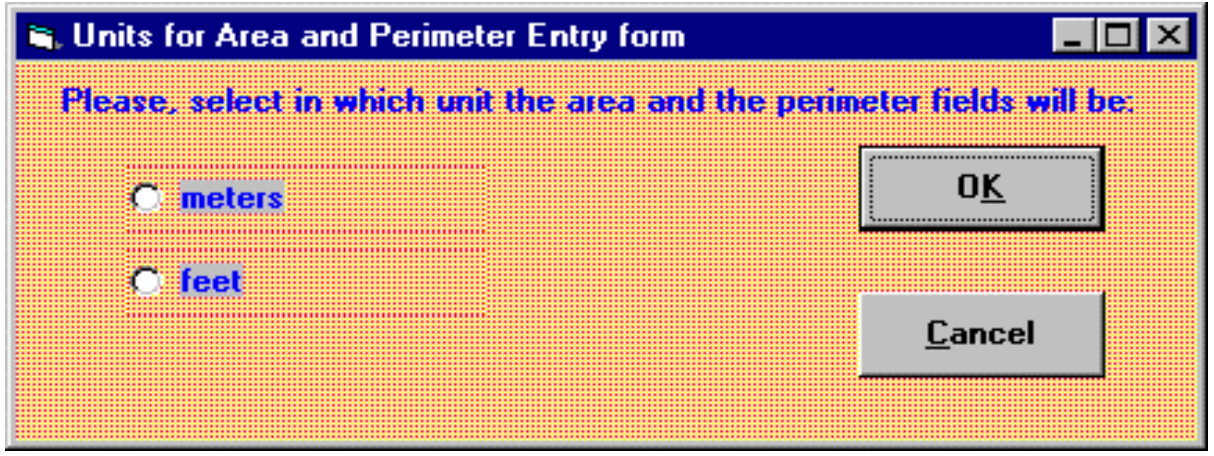

\section{Step 9: Delete Records}

The command Delete Records will delete those records from the Cadastre tables that no longer exist in the REMIS Oracle Database. It will delete the records and the polygons related to those records.

1. A form appears with fields that you will need to complete with information to allow the connection to the REMIS Oracle Database and with the project id and which state the project is located in.

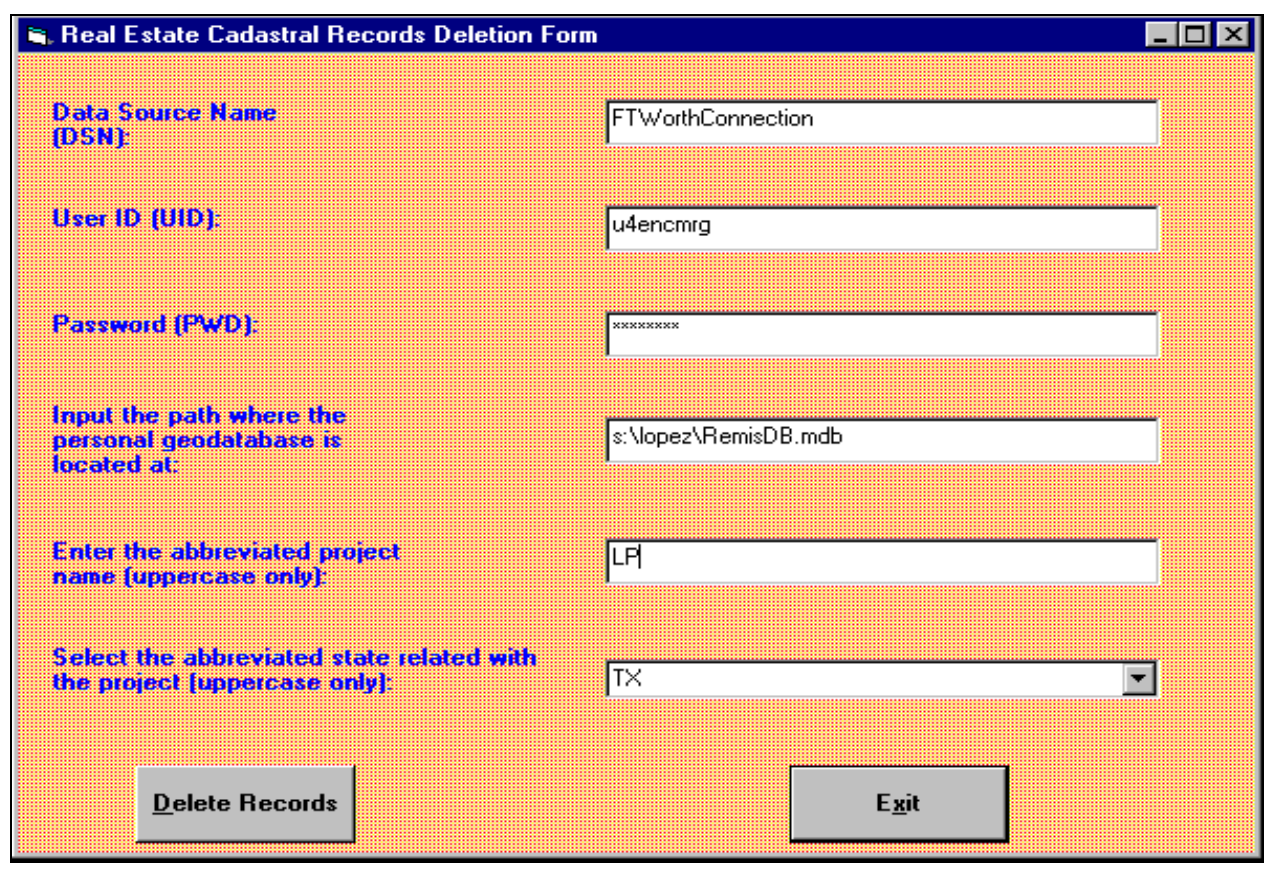

2. Select the Delete Records button after the information is entered to start the deletion of the records that no longer exist in the REMIS Oracle Database.

3. A List Box form appears, informing the user about the deletion routine. 
4. Refresh the database by clicking on the geodatabase and then pressing the F5 key.

\section{Step 10: Exit the Cadastral Real Estate Geodatabase Tool}

1. Close all forms when you are ready to exit the geodatabase.

2. The command Exit Form in the form will close the Geodatabase Tools form and the program.

\section{Final Notes about the Tool}

After the GeoDBTool button is clicked once, it becomes disabled. To enable the button again, do the following:

1. Click on the Tools menu.

2. Select Customize. The GeoDBTool becomes enabled again.

3. Close the Customize Window.

4. If you want to take the button out of the tool bar, click on it and drag it anywhere in the screen. This will make the button disappear.

Another way to enabled it is by exiting ArcCatalog (or ArcMap) and then open the applications again. 


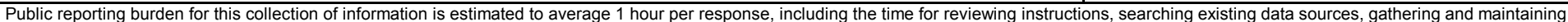

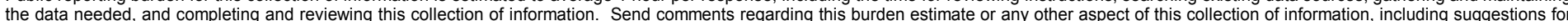

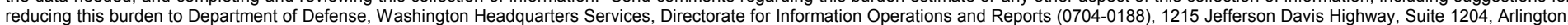

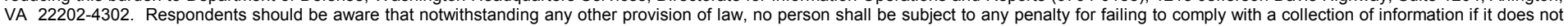
display a currently valid OMB control number. PLEASE DO NOT RETURN YOUR FORM TO THE ABOVE ADDRESS.
1. REPORT DATE (DD-MM-YYYY)
2. REPORT TYPE
3. DATES COVERED (From - To)

August 2001

Final report

\section{TITLE AND SUBTITLE}

GIS-Assisted Spatial Data Management for Corps of Engineers Real Estate Activities

5a. CONTRACT NUMBER

5b. GRANT NUMBER

5c. PROGRAM ELEMENT NUMBER

6. AUTHOR(S)

Linda Peyman Dove, Mark Graves, and Evelyn Lopez 5d. PROJECT NUMBER

5e. TASK NUMBER

5f. WORK UNIT NUMBER

33181

8. PERFORMING ORGANIZATION REPORT NUMBER

ERDC/EL TR-01-22

3530 Manor Drive, Suite 4

Vicksburg, MS 39180
Development Center

Environmental Laboratory

3909 Halls Ferry Road

Vicksburg, MS 39180-6199

9. SPONSORING / MONITORING AGENCY NAME(S) AND ADDRESS(ES)

U.S. Army Corps of Engineers

Washington, DC 20314-1000
10. SPONSOR/MONITOR'S ACRONYM(S)

11. SPONSOR/MONITOR'S REPORT NUMBER(S)

\section{DISTRIBUTION / AVAILABILITY STATEMENT}

Approved for public release; distribution is unlimited.

\section{SUPPLEMENTARY NOTES}

\section{ABSTRACT}

This report summarizes the research results to develop and demonstrate a geographic information system (GIS) assisted approach to meet the spatial data management and analysis demands of the Corps real estate activities. The report includes an overview of the cadastre Real Estate GIS database design that is compliant with the CADD/GIS Technology Center Spatial Data Standards and the cadastre Real Estate GIS software tool that implements the SDS-compliant cadastre real estate GIS database design in the objectoriented ArcInfo 8 software and that populates the database by linking to the non-spatial Real Estate Management Information System (REMIS). A test implementation of a cadastre Real Estate GIS at Lake of the Pines, Texas, is also presented.

\begin{tabular}{|c|c|c|c|c|c|}
\hline $\begin{array}{l}\text { 15. SUBJECT TERM } \\
\text { Cadastral } \\
\text { Cadastre }\end{array}$ & \multicolumn{2}{|c|}{$\begin{array}{l}\text { Geodatabase } \\
\text { Geographic information system } \\
\text { GIS }\end{array}$} & \multicolumn{3}{|c|}{$\begin{array}{l}\text { Real Estate Management Information System Spatial Data Standards } \\
\text { Real estate } \\
\text { REMIS }\end{array}$} \\
\hline \multicolumn{3}{|c|}{ 16. SECURITY CLASSIFICATION OF: } & $\begin{array}{l}\text { 17. LIMITATION } \\
\text { OF ABSTRACT }\end{array}$ & $\begin{array}{l}\text { 18. NUMBER } \\
\text { OF PAGES }\end{array}$ & $\begin{array}{l}\text { 19a. NAME OF RESPONSIBLE } \\
\text { PERSON }\end{array}$ \\
\hline $\begin{array}{l}\text { a. REPORT } \\
\text { UNCLASSIFIED }\end{array}$ & $\begin{array}{l}\text { b. ABSTRACT } \\
\text { UNCLASSIFIED }\end{array}$ & $\begin{array}{l}\text { c. THIS PAGE } \\
\text { UNCLASSIFIED }\end{array}$ & & 57 & $\begin{array}{l}\text { 19b. TELEPHONE NUMBER (include } \\
\text { area code) }\end{array}$ \\
\hline
\end{tabular}

